\title{
Intracellular amorphous Ca-carbonate and magnetite biomineralization by a magnetotactic bacterium affiliated to the Alphaproteobacteria
}

\author{
Caroline L. Monteil $\mathbb{1}^{1,2} \cdot$ Karim Benzerara ${ }^{2}$ - Nicolas Menguy ${ }^{2} \cdot$ Cécile C. Bidaud $^{1,2} \cdot$ Emmanuel Michot-Achdjian $^{1} \cdot$ \\ Romain Bolzoni $^{1,2} \cdot$ François P. Mathon $^{1,3} \cdot$ Margot Coutaud $^{2} \cdot$ Béatrice Alonso $^{1} \cdot$ Camille Garau $^{1} \cdot$ Didier Jézéquel $^{3}$. \\ Eric Viollier ${ }^{3}$. Nicolas Ginet ${ }^{4} \cdot$ Magali Floriani $\mathbb{1}^{5} \cdot$ Sufal Swaraj $^{6} \cdot$ Martin Sachse $^{7} \cdot$ Vincent Busigny $^{3,8}$.

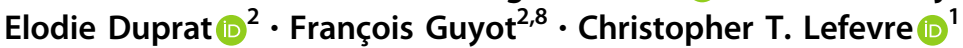

Received: 1 May 2020 / Revised: 30 July 2020 / Accepted: 10 August 2020 / Published online: 24 August 2020

(c) The Author(s), under exclusive licence to International Society for Microbial Ecology 2020

\begin{abstract}
Bacteria synthesize a wide range of intracellular submicrometer-sized inorganic precipitates of diverse chemical compositions and structures, called biominerals. Their occurrences, functions and ultrastructures are not yet fully described despite great advances in our knowledge of microbial diversity. Here, we report bacteria inhabiting the sediments and water column of the permanently stratified ferruginous Lake Pavin, that have the peculiarity to biomineralize both intracellular magnetic particles and calcium carbonate granules. Based on an ultrastructural characterization using transmission electron microscopy (TEM) and synchrotron-based scanning transmission X-ray microscopy (STXM), we showed that the calcium carbonate granules are amorphous and contained within membrane-delimited vesicles. Single-cell sorting, correlative fluorescent in situ hybridization (FISH), scanning electron microscopy (SEM) and molecular typing of populations inhabiting sediments affiliated these bacteria to a new genus of the Alphaproteobacteria. The partially assembled genome sequence of a representative isolate revealed an atypical structure of the magnetosome gene cluster while geochemical analyses indicate that calcium carbonate production is an active process that costs energy to the cell to maintain an environment suitable for their formation. This discovery further expands the diversity of organisms capable of intracellular Ca-carbonate biomineralization. If the role of such biomineralization is still unclear, cell behaviour suggests that it may participate to cell motility in aquatic habitats as magnetite biomineralization does.
\end{abstract}

These authors contributed equally: Caroline L. Monteil, Karim Benzerara, Nicolas Menguy

Supplementary information The online version of this article (https:// doi.org/10.1038/s41396-020-00747-3) contains supplementary material, which is available to authorized users.

$\triangle$ Christopher T. Lefevre

christopher.lefevre@cea.fr

1 Aix-Marseille University, CNRS, CEA, UMR7265 Institute of Biosciences and Biotechnologies of Aix-Marseille (BIAM), CEA Cadarache, F-13108 Saint-Paul-lez-Durance, France

2 Sorbonne Université, Muséum National d'Histoire Naturelle, UMR CNRS 7590, IRD. Institut de Minéralogie, de Physique des Matériaux et de Cosmochimie (IMPMC), 4 Place Jussieu, 75005 Paris, France

3 Université de Paris, Institut de Physique du Globe de Paris, CNRS, F-75005 Paris, France

\section{Introduction}

Biomineralization is a process whereby organisms trigger the formation of minerals by sequestering diverse chemical elements such as $\mathrm{Fe}, \mathrm{Mn}, \mathrm{Ca}, \mathrm{As}, \mathrm{O}, \mathrm{S}$ or $\mathrm{P}$ into relatively stable solid phases [1,2]. Produced minerals are chemically diverse

4 Laboratoire de Chimie Bactérienne, UMR 7283 CNRS, AixMarseille Université, Institut de Microbiologie de la Méditerranée, 13402 Marseille, France

5 Institut de Radioprotection et de Sûreté Nucléaire (IRSN), PRPENV/SERIS/LECO, Cadarache, Saint-Paul-lez-Durance 13115, France

6 Synchrotron SOLEIL, L'Orme des Merisiers, Saint-Aubin-BP 48, 91192 Gif-sur-YVETTE cedex, France

7 Ultrastructural Bioimaging unit, Institut Pasteur, 24-28 rue du Docteur-Roux, 75015 Paris, France

8 Institut Universitaire de France, 75005 Paris, France 
including oxides, oxy-hydroxides, carbonates, phosphates, sulphates and sulphides, some of which involve metals and metalloids [2]. This process can have a significant impact on the geochemical cycles of these diverse chemical species. Two types of biomineralization pathways are distinguished: (i) biologically-induced mineralization, which refers to all cases where mineral precipitation results from chemical shifts in the environment of the organisms induced by their metabolic activity, and (ii) biologically controlled mineralization, for which specific genes and cell structures are involved [3].

Biomineralization is not restricted to eukaryotes; many prokaryotes developed mechanisms to nucleate and grow diverse minerals as well. However, only few cases of controlled biomineralization are reported in prokaryotes. The most emblematic case of prokaryotic controlled biomineralization is that of magnetotactic bacteria (MTB), which produce intracellular magnetic crystals enclosed within compartments delimitated by a lipid bilayer and called magnetosomes [4]. The underlying genetic determinism, molecular machinery, ecologic role and evolution of this biomineralization pathway have been the focus of interdisciplinary investigations and represent the most documented case of biomineralization in prokaryotes $[5,6]$.

A much less documented case is provided by bacteria biomineralizing intracellular calcium carbonate inclusions. Two phylogenetically distinct groups have been shown to be capable of this biomineralization: (i) several species of the Cyanobacteria phylum, and (ii) some Achromatium species in the Gammaproteobacteria class. The large sulphur bacterium Achromatium oxaliferum was first described by Schewiakoff in 1893 [7]. It accumulates numerous calcium carbonate inclusions filling most of the cell volume [8-11]. This group of Proteobacteria was observed worldwide in the microoxic-anoxic zone of the sediment-water interface of both freshwater and marine environments. Population densities can be as high as $10^{5}$ cells $/ \mathrm{mL}$ and account for over $90 \%$ of the total local bacterial volume $[9,10,12]$. Despite the large biomass represented by Achromatium populations, their impact on biogeochemical cycles is not well understood. However, it has been shown that calcium carbonates accumulating within Achromatium cells can represent most of the solid calcium in some sediments, especially when (extracellular) pore waters are undersaturated with calcium carbonate phases [12-14]. No cultured representative strain is available, which limits the physiological characterization of cells to cultureindependent field and microcosm analyses. Only some Achromatium populations have been shown to be able to fix inorganic carbon, while others are not able to do so. Since all Achromatium populations can form intracellular Cacarbonates, this suggests that inorganic $\mathrm{C}$ fixation is not key to intracellular Ca-carbonate biomineralization. Moreover, they gain energy from sulphur oxidation and may use oxygen or nitrate as potential electron acceptors [15-19]. Transmission electron microscopy (TEM) analyses suggested the presence of membranes surrounding the calcium carbonate inclusions of Achromatium [12, 13].

The biomineralization of intracellular amorphous calcium carbonate (ACC) by phylogenetically and geographically widespread cyanobacteria species, has been discovered more recently [19]. They include deepbranching species, suggesting the possibility that intracellularly calcifying cyanobacteria may have thrived on the early Earth. Similarly to Achromatium, it was shown that they can form intracellular ACC even in extracellular solutions undersaturated with respect to ACC, again demonstrating some energy cost which has been attributed to active uptake of $\mathrm{Ca}$ [20]. Also similar with Achromatium, ACC biomineralization in cyanobacteria occurs within a microcompartment but in this case, it is delimited by an envelope that is not composed of a lipid bilayer but of a yetto-be-determined nature [21]. Two distinct patterns of ACC distribution were described within the cyanobacterial cells: one with ACC inclusions scattered throughout the cell cytoplasm and another one in which inclusions start forming at the septum and lie at the cell poles after cell division [22, 23]. In contrast to Achromatium, ACC-producing cyanobacteria were shown to live in oxic environments where they perform oxygenic photosynthesis [23]. These cyanobacteria can be abundant in some habitats. For example, they reach up to $10 \%$ of all the operational taxonomic units (OTUs) identified in a geothermal pool at Little Hot Creek in California [24]. Due to its ability to sequester abundant alkaline earth elements within ACC, the cyanobacterium Gloeomargarita lithophora [19, 25], was shown to be particularly interesting for the remediation of radionuclides such as ${ }^{90} \mathrm{Sr}$ and $\mathrm{Ra}[20,26]$. Moreover, this cyanobacterium is the closest modern relative of plastids, questioning the possibility that this capability to sequester $\mathrm{Ca}$ was transferred to the first photosynthetic eukaryotes [27].

The biological role of intracellular calcium carbonate biomineralization is still unclear, but some functions have been hypothesized: intracellular carbonates may be involved in (i) the buffering of intracellular $\mathrm{pH}[10,28]$, (ii) a buoyancy-regulating mechanism [13, 17, 19, 29] or (iii) the storage of inorganic carbon that may serve in some cases as an electron acceptor in carbonate respiration $[13,17]$. However, in both Cyanobacteria and Achromatium, the biochemical pathways and the genetic determinants involved in calcium carbonate formation remain unknown. Moreover, the evolutionary history of this process has yet to be determined to test whether it appeared independently in distinct phyla by convergent evolution, or derived from a common ancestor, and/or spread by transfer. 
For this purpose, a better assessment of the biology and ecology of intracellular calcium carbonate biomineralizing bacteria as well as the phylogenetic distribution of this capability is crucial. Considering that this process was detected only very recently in cyanobacteria, it is likely that we do not have an exhaustive view of the phylogenetic distribution of intracellular calcium carbonate biomineralization, and much less of the ecological niches where such a biomineralization is performed.

Recent observations in the ferruginous and permanently stratified (meromictic) Lake Pavin, Massif Central, France [30], support this assumption by revealing intracellular calcium carbonates biomineralizing microorganisms within a broad uncharacterized diversity of biomineralizing microorganisms. Here, we report a magnetotactic bacterium in the water column and sediments of Lake Pavin that biomineralizes both intracellular magnetite and calcium carbonate. Molecular typing of single cells sorted from sediments revealed that the double biomineralization is performed by members of an undescribed genus within Alphaproteobacteria with no close MTB relatives. Hereafter, we characterize the ultrastructure and intracellular mineral phases biomineralized by these bacteria to finally give some insight into magnetite biomineralization using a partial genome sequence.

\section{Materials and methods}

\section{Site description and sample collection}

Sediment samples were collected from the shore of Lake Pavin. This was done by fully filling $1 \mathrm{~L}$ glass bottles with $300-400 \mathrm{~mL}$ of sediments and $600-700 \mathrm{~mL}$ of water overlaiding the sediments. Air bubbles were excluded. Once in the laboratory, bottles were stored with their cap closed, under dim light and at room temperature (ca. $25^{\circ} \mathrm{C}$ ). Two locations were sampled at Lake Pavin during the different sampling campaigns that took place between May 2015 and October 2019: (i) $45.499107^{\circ} \mathrm{N}, 2.886273^{\circ} \mathrm{E}$ and (ii) $45.499101^{\circ} \mathrm{N}, 2.889239^{\circ} \mathrm{E}$.

Water column samples were collected in October 2018 at depths ranging between 45 and $65 \mathrm{~m}$ from a platform located near the centre of Lake Pavin $\left(45.495792^{\circ} \mathrm{N}\right.$, $2.888117^{\circ} \mathrm{E}$ ). Water was collected using a Niskin bottle at the targeted depths and was then transferred in $1 \mathrm{~L}$ glass bottles filled to their capacity and tightly closed. Bacteria of interest collected from the water column could be conserved for a few days only when stored at $4{ }^{\circ} \mathrm{C}$, whereas those from sediments could be observed and magnetically sorted up to 5 years after their sampling and storage in the laboratory, at room temperature. This is the reason why the majority of our study focused on bacteria from sediments.

\section{Solution chemistry analyses}

Solutions in the sampling bottles were filtered at $0.22 \mu \mathrm{m}$ before analyses. The $\mathrm{pH}$ was measured with a CyberScan pH 5500 pH-metre (Eutech instruments) using a combined pH microelectrode (Fisherbrand) calibrated with Hanna pH standard buffer solutions $(4.010,7.010,10.010)$ and an uncertainty of $0.01 \mathrm{pH}$ unit. Elemental analyses of $\left[\mathrm{Ca}^{2+}\right]$ were performed on samples acidified with $\mathrm{HNO}_{3}(2 \%)$ by ICP-AES (iCAP6200 Thermofisher) with an uncertainty of $0.7 \%$. All measurements were far above the quantification limit (ca. 0.1 ppb).

\section{Dissolved orthophosphate concentration and alkalinity of sediment pore water}

Alkalinity measurements were carried out according to the protocol previously described $[31,32]$. The standard range was tested with Evian ${ }^{\oplus}$ water before sample alkalinity measurements. Here, alkalinity was approximately equivalent to the concentration of $\mathrm{HCO}_{3}{ }^{-}$under the present conditions [33].

The saturation index was defined as: $\mathrm{SI}=\log$ (IAP/ $\mathrm{K}_{\mathrm{sp}}$ ), where IAP corresponds to the ion activity product and $\mathrm{K}_{\mathrm{sp}}$ to the thermodynamic solubility product for a mineral phase. A solution was supersaturated with respect to a mineral phase when $\mathrm{SI}>0$. Here $\mathrm{Ca}^{2+}$ and $\mathrm{HCO}_{3}{ }^{-}$ activities were approximated to the measured concentrations. The solubility constant $\left(\mathrm{pK}_{\mathrm{sp}}\right)$ at $25^{\circ} \mathrm{C}$ of amorphous Ca carbonate (ACC) used in the present study was 6.278, as determined by Purgstaller et al. [34].

\section{Magnetic enrichment and light microscope observation}

North-seeking magnetic cells were concentrated by placing the south pole of a neodymium-iron-boron magnet (disc magnet with a diameter of $5 \mathrm{~mm}$ and a height of $5 \mathrm{~mm}$ ) for $3 \mathrm{~h}$ next to the bottles, above the sediment-water interface (for the sediment samples) or at mid-height against the bottle (for water column samples). Examination of magnetically concentrated cells was carried out using the hanging drop technique [35] under a Zeiss Primo Star light microscope equipped with phase-contrast and differential interference contrast optics. Magnetotaxis was evidenced by rotating a stirring bar magnet at $180^{\circ}$ on the microscope stage to reverse the local magnetic field. Motility and the magnetotactic behaviour were also observed and recorded under a Leica LMD6000 light microscope equipped with a Leica DMC 4500 camera. 


\section{In situ and in microcosms measurements of chemical and cell count profiles}

Dissolved oxygen profiles were measured in the sediments, using a fibre-optic oxygen sensor $(50-\mu \mathrm{m}$ tip diameter, REF OXR50) and a FireSting $\mathrm{O}_{2}$ metre, both from Pyroscience. High-resolution profiles $(100 \mu \mathrm{m}$ steps, from $10 \mathrm{~mm}$ above the sediment to $-25 \mathrm{~mm}$ below the sediment) were achieved with a Pyroscience MU1 motorized micromanipulator. Sensor calibration was made against saturated humid air $\left(\mathrm{O}_{2}\right.$ sat. $\left.=100 \%\right)$ and a water solution flushed with $\mathrm{N}_{2}$. Magnetotactic cells were highly concentrated and diverse in sediment samples, those with large refractive granules could be easily distinguishable from other bacteria and sediment particles; they were counted using a Malassez counting chamber. Measurements were systematically carried out on three replicates of three different samples. For each replicate, the number of cells was counted at three different locations in the sediment sample. Cell counts were reported as the means of triplicate counts for each sample.

In the water column, dissolved oxygen and redox potential were measured in situ using a CTD $\mathrm{O}_{2}$-pH-redox probe (YSI 6600). Three $1 \mathrm{~L}$ bottles of water were collected every metre above and below the oxycline in order to determine the depth distribution of magnetotactic bacteria. For each depth, three drops of $40 \mu \mathrm{L}$ were observed using the hanging drop technique [35]. Magnetotactic cells accumulating at the edge of the drops when a magnetic field was applied from one side of the drop were counted under a ZEISS Primo Star light microscope. The number of cells counted in each drop was multiplied by a factor of 25 to obtain the concentration of cells per millilitre. Cell counts were reported as the means of triplicate counts for each depth.

\section{Cell sorting and whole-genome amplification (WGA)}

Cell sorting was carried out on sediment samples collected in Lake Pavin with an InjectMan NI2 micromanipulator and a CellTram vario, hydraulic, manual microinjector from Eppendorf mounted on a Leica DM IL LED microscope equipped with a $63 \times / 0.70 \mathrm{PH}$ objective. The microscope and micromanipulator were placed inside a clean chamber, sterilized beforehand by $1 \mathrm{~h}$ germicidal irradiation with ultraviolet (wavelength of the lamp: $254 \mathrm{~nm}$ ). A $10-\mu \mathrm{L}$ drop containing magnetically concentrated cells was gently added to a $30-\mu \mathrm{L}$ drop of filtered Lake Pavin water on a hydrophobic coverslip in order to magnetically transfer magnetotactic cells toward the filtered water. One to ten cells with bright granules were transferred with a sterile microcapillary (TransferTip ${ }^{\oplus}$ (ES), $4 \mu \mathrm{m}$ inner diameter, Fig. S1) into a $4 \mu \mathrm{L}$ drop of phosphate buffer saline (PBS). This drop was stored at $-20^{\circ} \mathrm{C}$ before WGA. To obtain sufficient gDNA for 16S rRNA gene and shotgun metagenomic sequencing, WGA was carried out using the multiple displacement amplification (MDA) technique with the REPLI-g Single Cell Kit (QIAGEN) following the manufacturer's instructions. The concentration of double strand gDNA was measured using a $\mathrm{QuBit}^{\mathrm{TM}} 4$ fluorimeter (ThermoFisher Scientific).

\section{Cloning and sequencing of the $16 \mathrm{~S}$ rRNA gene of magnetically concentrated and sorted cells}

The 16S rRNA gene of all processed DNA samples was amplified using the Phusion Hot Start Flex DNA Polymerase following the manufacturer's recommendations, a DNA template of $50-70 \mathrm{ng} / \mu \mathrm{L}$ and the $27 \mathrm{~F} 5^{\prime}$-AGAGT TTGATCMTGGCTCAG-3' ${ }^{\prime}$ and $1492 \mathrm{R}$ 5'-TACGGHTA CCTTGTTACGACTT- $3^{\prime}$ primers [36]. Blunt-end fragments of 16S rRNA gene sequences were cloned using a Zero Blunt ${ }^{\circ} \mathrm{TOPO}^{\circ} \mathrm{PCR}$ Cloning Kit with One Shot TOP10 chemically competent $E$. coli cells. The inserts of the resulting clones were digested using the restriction enzyme EcoRI to select five operational taxonomic units (OTUs) representative of the sediment-sorted-cell populations and were sent for sequencing (Eurofins Genomics Germany $\mathrm{GmbH}$ ). Sequences were compared to data from the NCBI nucleotide database with Basic Local Alignment Search Tool [37]. The 16S rRNA gene sequences of the sorted MTB OTUs were checked using the UCHIME2 chimera detection algorithm [38] and deposited in GenBank under accession numbers MT021453 to MT021457.

\section{Phylogenetic analyses}

All the 16S rRNA gene sequences of Rhodospirillaceae and Acetobacteraceae type strains (NCBI taxonomy) available in the public databases NCBI in January 2020 were downloaded and completed with the five OTUs obtained in this study. This database was reduced to one species per genus keeping the highest quality sequences to draw a first tree with the BioNJ software [39] after sequences were aligned using MAFFT 7 [40] and trimmed with the relaxed parameters of Gblocks (Fig. S2) [41]. This tree was used to remove genetic redundancy by randomly selecting few representative species only per cluster to get a final database of 45 sequences including 7 Acetobacteraceae type strains as an external group. All sequences were aligned and trimmed following the same method to get a final alignment of $1381 \mathrm{bp}$. A maximum-likelihood tree was built using IQTREE [42] and a TIM3 $+\mathrm{F}+\mathrm{R} 4$ model for describing nucleotide evolution selected by Modelfinder [43] using the Bayesian Information Criterion (BIC). Robustness of tree topology was tested using a non-parametric bootstrap approach and 500 replicates. 


\section{Correlative fluorescent in situ hybridization (FISH) and scanning electron microscopy (SEM)}

FISH was performed according to the procedure described by Pernthaler et al. [44]. First, an ATTO488-labelled probe was designed, specific to the bacteria producing refractive inclusions that were sorted from sediment samples (CCPp, 5'- GTCATTATCGTCGCGTGCGAAAGAGCTTTACAA CCCG $-3^{\prime}$, complementary to nucleotides 383 to 419 of the $16 \mathrm{~S}$ rRNA molecule of OTU1, one mismatch with OTU5 at position 414). This was based on the alignment of the most similar 16S rRNA gene sequences of the Rhodospirillaceae family found in GenBank in August 2018. Probe specificity was evaluated by using the PROBE_MATCH programme in the RDP-II [45]. The nearest non-target hits contain at least one mismatch with the specific probe CCPp. Oligonucleotide probes used in this study were purchased from Eurofins Genomics (Ebersberg, Germany).

Then, a $20 \mu \mathrm{L}$ drop of magnetically concentrated cells was deposited on an $18 \mathrm{~mm} \times 18 \mathrm{~mm}$ coverslip covered with poly-L-lysine. After $10 \mathrm{~min}$, the drop was removed and the cells adsorbed on the coverslip were fixed overnight with $30 \mu \mathrm{L}$ of a $4 \%$ paraformaldehyde solution. Fixed cells were dehydrated by serial incubations in 50\%, $80 \%$ and $100 \%$ ethanol during $5 \mathrm{~min}$ each. The hybridization solution contained $10 \mathrm{ng} / \mathrm{mL}$ of the probe, $0.9 \mathrm{M}$ $\mathrm{NaCl}, 20 \mathrm{mM}$ Tris-HCl (pH 7.4), $1 \mathrm{mM} \mathrm{Na} 2$ EDTA, and $0.01 \%$ sodium dodecyl sulphate (SDS), using the hybridization and washing stringencies recommended for each probe ( $30 \%$ for CCPp). Hybridization was performed at $46^{\circ} \mathrm{C}$ for $2 \mathrm{~h}$. For some samples, $10 \mu \mathrm{L}$ of a solution of 1 $\mu \mathrm{g} / \mathrm{mL}$ of 4,6-diamidino-2-phenyl- indole (DAPI) was added to the coverslip, incubated $10 \mathrm{~min}$ at $4{ }^{\circ} \mathrm{C}$ and rinsed with water. Coverslips were stored at $4{ }^{\circ} \mathrm{C}$ in a humidity chamber before observation.

Finally, hybridization assays were analysed using a Zeiss LSM780 confocal microscope available on the ZooM platform at the Institute of Biosciences and Biotechnologies of Aix-Marseille. Correlative fluorescence light and electron microscopy, combining the specificity of fluorescence labelling with the high spatial resolution of scanning electron microscopy (SEM), was carried out with a Zeiss LSM710 confocal laser scanning microscopy at the Institut de Minéralogie, de Physique des Matériaux et de Cosmochimie in Paris. Correlation with SEM was performed using the KorrMik Life Sciences sample holder and the correlative Shuttle and Find software implemented in ZEN as previously described [46]. Images were collected in the backscattered and secondary electron modes using a Zeiss Ultra 55 FEG-SEM operating at $10 \mathrm{kV}$, a working distance of $5 \mathrm{~mm}$ and an aperture of $30 \mu \mathrm{m}$.

\section{Transmission electron microscopy (TEM)}

The ultrastructure of $\mathrm{CaCO}_{3}$-producing MTB was observed by developing an alternative protocol to fix cells on a TEM carbon-coated grid. Indeed, only few or no cell at all of $\mathrm{CaCO}_{3}$-producing MTB were fixed on TEM grids when using the standard protocol consisting simply in drying a droplet containing the bacteria. Here, we pipetted $2 \mu \mathrm{L}$ of liquid from the edge of the northern side of a hanging drop, at the bottom of the drop, where magnetic cells aggregated and settled down due to their magnetotactic behaviour and their density. Then, we slowly deposited these cells at the centre of the TEM grid. The grid and the drop were kept in place during the fixation of the cells. Indeed, if the grid was moved upside down as it is usually done for other MTB, cells with $\mathrm{CaCO}_{3}$ granules did not adsorb onto the carbon film of the TEM grid and instead settled down at the bottom of the drop likely because of their high density. Once the drop started to dry, the grid was washed with filtered deionized water. Although most of the $\mathrm{CaCO}_{3}$-producing bacteria formed large aggregates of cells, this technique facilitated their observation and enabled optimal adsorption of the MTB onto the carbon film.

Electron micrographs were recorded with a Tecnai $\mathrm{G}^{2}$ BioTWIN (FEI Company) equipped with a CCD camera (Megaview III, Olympus Soft imaging Solutions GmbH) using an accelerating voltage of $100 \mathrm{kV}$. High-resolution transmission microscopy (HRTEM), z-contrast imaging in the high-angle annular dark field (STEM-HAADF) mode, and elemental mapping by X-ray energy-dispersive spectrometry (XEDS) were carried out using a JEOL $2100 \mathrm{~F}$ microscope. This machine, operating at $200 \mathrm{kV}$, was equipped with a Schottky emission gun, an ultrahigh resolution pole piece, and an ultrathin window JEOL XEDS detector. HRTEM images were obtained with a Gatan US4000 charge-coupled-device (CCD) camera.

The sizes of magnetosomes and other mineral inclusions as well as the estimation of the area occupied by these inclusions were measured from TEM images using the ImageJ software $(1.48 \mathrm{v})$.

\section{Cryo-electron microscopy of vitreous sections (CEMOVIS)}

For CEMOVIS, a pellet of cells magnetically enriched from a Lake Pavin sediment sample was harvested. The pellet was carefully mixed with an equal volume of $40 \%$ PBS. The suspension was transferred in a gold coated cupper sample holder type A with a $200-\mu \mathrm{m}$ diameter cavity and closed with a flat sample holder type B (Wohlwend GmbH, Sennwald, Switzerland) before vitrification with a HPM 100 (Leica microsystems, Vienna, Austria). Vitrified samples 
were placed in the cryo-chamber of a Leica cryoultramicrotome at $-150{ }^{\circ} \mathrm{C}$. Ultrathin cryo-sections with a nominal feed of $40 \mathrm{~nm}$ were obtained using a $35^{\circ}$ cryodiamond knife and were collected on quantifoil grids covered with a carbon film. Grids were stored in liquid nitrogen before observations by cryo-TEM in the low dose mode with a Tecnai G2 microscope equipped with a Gatan US 4000 CCD camera.

\section{Shotgun genomic sequencing, assembly and functional annotation}

One single-cell of $\mathrm{CaCO}_{3}$-producing MTB, named CCP1 (Calcium Carbonate Producing bacterium \#1), was sorted using a micromanipulator (as described above) from a sample collected on the shore of Lake Pavin in May 2015. After WGA of this cell, gDNA was quantified using a QuBit Fluorimeter (ThermoFisher Scientific) and quality was evaluated on a $1 \%$ TAE agarose gel.

The genome of CCP1 was sequenced on an Illumina MiSeq platform with a MiSeq ${ }^{\circledR}$ Reagent Kit v2 (300 cycles, Illumina Inc.) using a Nextera XT kit for the library preparation. A total of $1.9 \times 10^{6}$ paired-end reads was obtained, trimmed and filtered using Trimmomatic [47] and the default settings. A draft assembly of $2.5 \mathrm{Mbp}$ was assembled using SPAdes v.3.12.0 (with -k 21,33,55,77,99,127 only-assembler — sc options) into 3365 contigs longer than $250 \mathrm{bp}$ and annotated using the fast method implemented in Prokka 1.14.0 [48]. The genome completeness was assessed using CheckM v1.1.2 [49].

\section{Scanning transmission X-ray microscopy (STXM)}

STXM analyses were performed on the HERMES beamline at the SOLEIL synchrotron (St. Aubin, France) [50, 51]. Details on the STXM technique and its application to biomineralization can be found in e.g., [52, 53]. This microscopy uses X-rays in the soft X-ray energy domain to provide images with a $\sim 25 \mathrm{~nm}$ spatial resolution and spatially-resolved speciation information of light elements such as $\mathrm{C}$ based on $\mathrm{X}$-ray absorption near edge structure (XANES) spectroscopy. For this purpose, monochromated $\mathrm{X}$-rays are focused to a $\sim 25 \mathrm{~nm}$ spot by a Fresnel zone plate. An image is obtained by positioning the sample at the focal point of the lens and raster scanning it in $x$ and $y$, while recording the intensity of the transmitted X-rays. After localizing cells of interest by optical microscopy beforehand, we could easily localize them by STXM. A stack of STXM images of the cells at a sequence of photon energies was acquired at the $\mathrm{C} \mathrm{K}$-edge. The step size was $75 \mathrm{~nm}$ and images were obtained at 140 energy steps varying between 270 and $345 \mathrm{eV}$ with an increment of 0.12 $\mathrm{eV}$ in the $282-291.5 \mathrm{eV}$ energy range, where most of the narrowest XANES peaks were present. The imaged area also contained a sub-area free of cells to measure the incident flux (I0). This allowed to convert images from transmitted intensity units to optical density units (OD). The XANES spectra at the $\mathrm{C}$ K-edge of the $\mathrm{CaCO}_{3}$ inclusions and the cells were extracted and mapped using the aXis 2000 software (McMaster University, http://unicorn.mcma ster.ca/axis/aXis2000-IDLVM.html).

\section{Results}

\section{Observation of bacteria with electron dense granules and an unusual magnetotactic behaviour}

Over the different sampling campaigns performed since 2015 at Lake Pavin, a large diversity of MTB morphotypes, mostly represented by cocci, was observed close to the oxic-anoxic boundary of the water column (45-60 m depth) [46]. MTB were also very diverse in the sediments collected from the shore down to a water depth of $40 \mathrm{~m}$ [54]. In most collected samples, one MTB morphotype escaped our first light and electron microscopy observations because of its atypical magnetotactic behaviour. Indeed, some slightly-curved rod-shaped MTB with large inclusions were only weakly magnetic, i.e., their rotation was slow compared to other MTB when the applied magnetic field was switched $180^{\circ}$ to the initial direction. They did not, for the majority, accumulate at the edge of the hanging drop. Instead, they aligned along the magnetic field and slowly swam back and forth at the bottom of the drop without reaching the edge of the drop where light microscopy observations of MTB usually focus (Fig. 1a). Overall, these particular MTB cells were more efficiently concentrated by increasing the duration of the magnetic enrichment from $30 \mathrm{~min}$ to $3 \mathrm{~h}$ and applying a stronger magnetic field (neodymium, iron and boron magnet of $400 \mathrm{mT}$ ). As most of the other members of the MTB community, these bacteria were located in oxygendepleted areas, i.e. below the oxycline [46]. The cell density of this new MTB morphotype in the water column was generally higher in autumn and its maximum was observed during the October 2018 campaign at a depth of $58 \mathrm{~m}$, reaching $4.0 \times 10^{2}$ cells $/ \mathrm{mL}$ (Fig. 1b). However, this cell density was probably underestimated since the used hanging drop technique likely biased the counting of such MTB downward. This new MTB morphotype was always observed in the hanging drop assay without previous magnetic enrichment in autumn. During the other seasons (spring and summer), they were observed after magnetic enrichment only (i.e., abundance $<25$ cells $/ \mathrm{mL}$ ). In sediment samples, these bacteria generally represented the dominant magnetotactic population and reached up to 


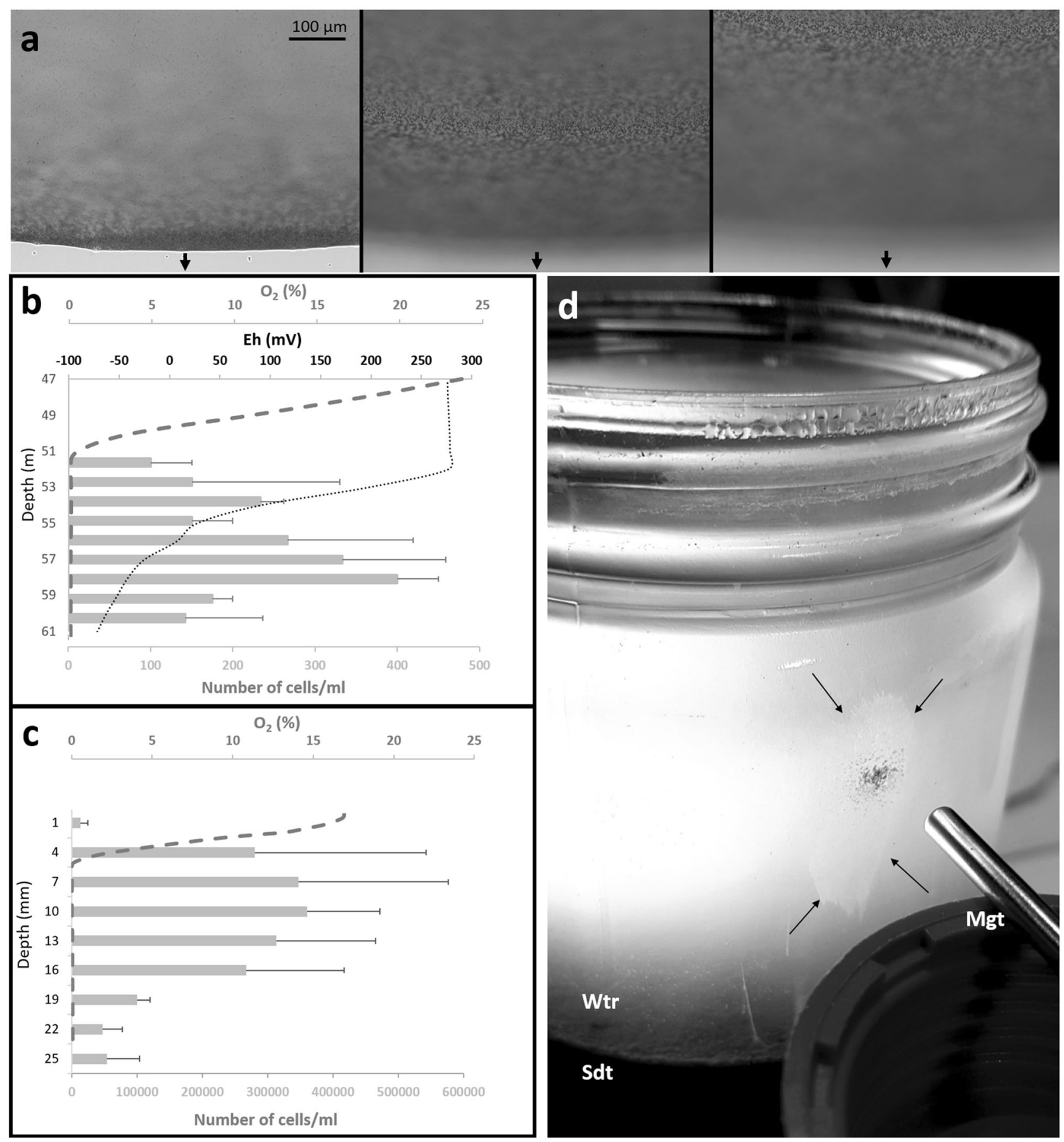

$5.8 \times 10^{5}$ cells $/ \mathrm{mL}$ of porewater. In the sediments, the majority of the cells were detected below the oxic-anoxic interface as in the water column (Fig. 1c). After magnetic enrichment of sediment samples, aggregated cells formed a thin irregular whitish pellet measuring up to $4 \mathrm{~cm}$ in diameter and located against the magnet. The pellet was wider below the magnet, suggesting that the population was sensitive to gravity (Fig. 1d). In most samples collected on the shore, MTB pellets aggregated after $3 \mathrm{~h}$ against magnets were of similar size whenever the north or the south poles of the magnets were directed toward the sampling bottle. This suggests that there was an equal proportion of north- and south-seeking cells.

Bacteria with this atypical magnetotactic behaviour contained 2 to 4 characteristic large refractive inclusions measuring $856 \pm 95 \mathrm{~nm}$ in width ( $n=147$, Fig. 2 ). They also showed poor adsorption onto the carbon film covering TEM grids and a specific protocol had to be developed for 
Fig. 1 Observation of the refractive magnetotactic bacterium from Lake Pavin. a Light microscope images of north-seeking magnetotactic bacteria (MTB) sampled in the sediment of Lake Pavin. The microscope was focused at the edge of the water drop closest to the south pole of the bar magnet, producing a local field direction indicated by the black arrow (left panel). The microscope was focused at $200 \mu \mathrm{m}$ (middle panel) and $400 \mu \mathrm{m}$ (right panel) from the edge of the water drop showing the presence of MTB cells (seen as grey dots in the images) aligned with the magnetic field but not aggregated at the edge of the hanging drop. b Vertical concentration profiles of oxygen (grey dashed line), redox potential (black dotted line) and rods with large refractive inclusions (histogram) through the water column of samples collected in Lake Pavin in October 17th, 2018. Note that the measurements extend through the oxic-anoxic interface and the deeper regions of the anaerobic zone of the water column. Cell counts are reported as the mean of triplicate measurements and line extensions represent the positive standard deviation of the total number of MTB. Rods with refractive inclusions were also observed above $52 \mathrm{~m}$ and below $60 \mathrm{~m}$ but at densities $<25$ cells $/ \mathrm{mL}$ and thus escaped our counting assay. c Vertical concentration profiles of $\mathrm{O}_{2}$ (grey dashed line) and cell density of rods with large refractive inclusions (histogram) in a sediment sample collected from the shore of Lake Pavin. Cell counts are reported as the mean of triplicate measurements and line extensions represent the positive standard deviation. $\mathbf{d}$ Image of a one-litre sample collected from the shore of Lake Pavin. The bottle was filled to about $1 / 3$ of its volume with sediment (Sdt) and the remainder of the bottle is filled to its capacity with water (Wtr) that overlaid the sediment. A large whitish pellet (black arrows) of magnetotactic cells clustered against the magnet (Mgt) $2 \mathrm{~h}$ after magnetic enrichment. Note the presence of black particles, in the centre of the pellet, composed of magnetic sediments.

their fixation on the grids (see Materials and Methods). Most of the cells formed large aggregates on the TEM grids. Analysis of the cells ultrastructure revealed the presence of a single polar flagellum (Fig. 2a). Inclusions were very dense to the electron beam and occupied the majority of the cytoplasm, which significantly complicated the observation of the magnetosomes using conventional TEM bright field mode (Fig. 2b, c). Magnetosomes overlapping with the inclusions were only observed when using the HAADF mode in STEM (Fig. 2d, e). Some inclusions were observed to form at the septum of dividing cells (Figs. 2f and S3). Shortly after cell division, each daughter cell contained two inclusions of different sizes: a large one located at the flagellum pole and a small one at the other pole (Figs. 2a, d, e and S3). When observed under the light microscope with an applied magnetic field, recently divided cells always showed their smallest inclusion in the front and their largest one in the back, at the flagellum pole (Fig. $2 \mathrm{~g}$ ). Based on the observation of 186 STEM-HAADF images of cells from a water column sample, two scenarios linking cell division and the formation of the inclusions could be proposed (Supplementary Information on cell division). However, we cannot exclude the possibility that different species or sub-species of calcium carbonate-producing MTB have different number and/or organization of inclusions.

\section{Chemical analyses indicate the presence of both calcium carbonate and magnetite inclusions forming in environmental conditions undersaturated with Ca-carbonate phases}

The majority of cells, from sediment samples, producing the large electron-dense inclusions contained a single chain of $14 \pm 4(n=35)$ prismatic magnetite particles measuring 58 $\pm 4 \mathrm{~nm}$ in length and $40 \pm 3 \mathrm{~nm}$ in width $(n=223)$ (Fig. 3a, c). Similar cells were also observed with cuboctahedral magnetite particles in the sediments (Fig. 3d, f). Moreover, cells producing such large inclusions in the water column were always observed with cuboctahedral particles. TEM image analysis revealed that these large electron-dense inclusions represent $73 \pm 9 \%(n=134)$ of the cell area. Usually, extrapolation from 2D TEM images to 3D volumes is not straightforward. Here, we assumed that both cell and electron-dense inclusions exhibited an ellipsoidal morphology, which is fairly supported by the numerous images of randomly oriented cells. Based on this assumption, the volume of the large electron-dense inclusions could be roughly estimated to $65 \%$ of the total cell volume. X-ray energy-dispersive spectrometry (XEDS) and elemental mapping in the STEM-XEDS mode indicated that the large inclusions contained mostly calcium, carbon and oxygen (Fig. 3b, e, Fig. S3 and Supplementary Information), with weak peaks assigned to strontium and barium (Fig. 4). Phosphorus-rich granules were also observed in some cells (Figs. 3b and 4b). Selected-area electron diffraction patterns obtained on these inclusions showed that they were amorphous (Fig. S4).

STXM analyses were carried out on MTB cells collected in the water column and the sediments to further characterize these amorphous Ca-, O- and C-containing inclusions. XANES spectra at the $\mathrm{C}$ K-edge extracted from the cells showed peaks at 285.2, 286.6, 288.2 and $290.3 \mathrm{eV}$ which were interpreted as carbon $1 \mathrm{~s} \rightarrow \pi^{*}$ electron transitions in aromatic, ketonic/phenolic, amide carbonyl and carbonate functional groups, respectively [55]. Spectra measured on large inclusions were very similar to those of reference amorphous calcium carbonate (ACC) particles and showed a pronounced $1 \mathrm{~s} \rightarrow \pi^{*}$ carbonate-C peak at $290.3 \mathrm{eV}$ together with broader peaks at 296.2 and $301.6 \mathrm{eV}$ that were attributed to a $1 \mathrm{~s} \rightarrow \sigma^{*}$ electron transitions in carbonate C. Overall, this allowed to unambiguously determine that inclusions in the MTB were composed of ACC [55] (Fig. 5).

In parallel, we measured the alkalinity (approximated to $\left.\left[\mathrm{HCO}_{3}{ }^{-}\right]\right), \mathrm{pH}$, and $\left[\mathrm{Ca}^{2+}\right]$ in 10 sampling bottles of onshore sediments to better understand the environmental conditions that led to the formation of such inclusions. The $\mathrm{pH}$ of the pore water was between 6.88 and $7.64 \pm 0.01$, the $\left[\mathrm{Ca}^{2+}\right]$ between $83.9 \pm 0.7$ and $634 \pm 3.7 \mu \mathrm{M}$ and the alkalinity 
Fig. 2 Microscopy images of magnetotactic bacteria with electron-dense inclusions isolated from Lake Pavin sediment samples.

a Transmission electron microscopy (TEM) image of a cell stained with $1 \%$ uranyl acetate, showing the presence of one single polar flagellum. b, $\mathbf{c}$ Bright-field TEM images of cells showing the electron-dense granules that make the observation of the magnetosomes difficult. d-f Scanning TEM-high-angle annular dark field (HAADF) images showing the magnetosome chain partially overlapping the electron-dense inclusions in the cytoplasm of the cells. $\mathbf{f}$ The formation of small inclusions at the septum of a dividing cell. $\mathbf{g}$ Light microscopy image of cells magnetically orientated in the same direction (north direction pointed by the black arrow) showing that the smaller inclusions are always at the front of the cells. Scale bars represent $1 \mu \mathrm{m}(\mathbf{a}-\mathbf{f})$ and $2 \mu \mathrm{m}(\mathbf{g})$.
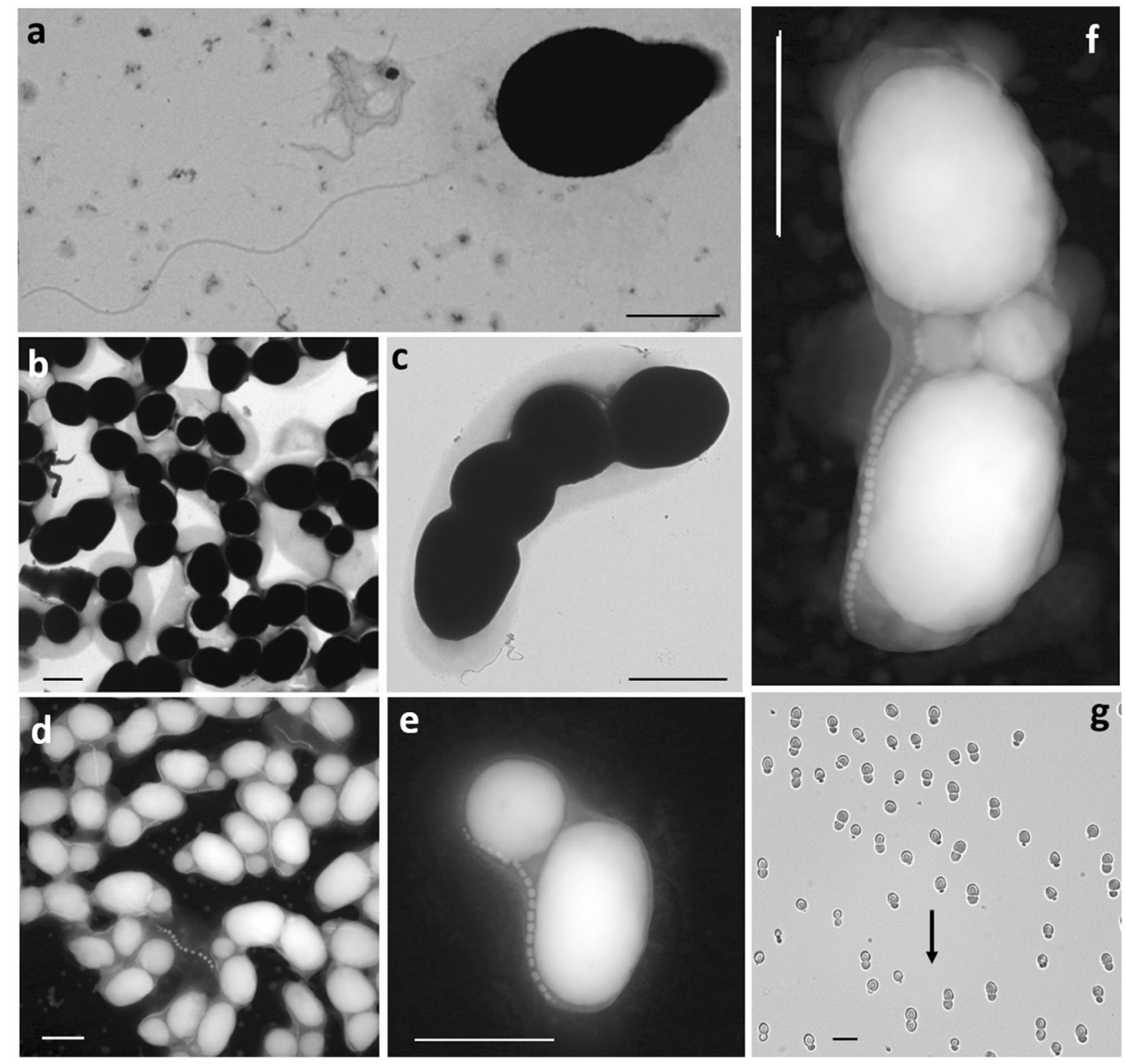

between 725 and $3824 \mu \mathrm{M}$. Overall, the ion activity product (IAP), $\left(\mathrm{Ca}^{2+}\right) \times\left(\mathrm{CO}_{3}{ }^{2-}\right)$, varied between $3.32 \times 10^{-11}$ and $1.23 \times 10^{-9}$ and was therefore systematically lower than the solubility products at $25^{\circ} \mathrm{C}$ of ACC $\left(5.27 \times 10^{-7}\right.$, [34] $)$ and calcite $\left(3.31 \times 10^{-9}\right)$. As a result, we could conclude that all solutions in contact with the sediments and MTB were undersaturated with ACC, at least at the bulk scale. Available water chemistry data indicate that ACC produced by MTB present in the water column also form in a solution undersaturated with ACC [56].

\section{ACC-producing MTB represent a new genus within the Alphaproteobacteria and harbour an atypical magnetosome gene cluster}

The identity of ACC-producing MTB isolated from the Lake Pavin sediments was investigated by sequencing the 16S rRNA genes amplified from magnetically purified populations and sorted single-cells (Fig. S1). We obtained 18 sequences (between 1450 and $1492 \mathrm{bp)}$ ) composed of 5 operational taxonomic units (OTUs) defined at a $99 \%$ identity level. These 5 OTUs shared $92.8-98.3 \%$ identity indicating that this morphotype of ACC-producing MTB was composed of several species, likely belonging to at least two genera based on a 95\% sequence identity threshold [57]. Based on BLASTN hits, the closest cultured species belonged to the Azospirillum and Skermanella genera of the Rhodospirillaceae family of the Alphaproteobacteria class (following the current NCBI taxonomy). However, sequence identities with these genera were low (between 91.7 and 93.8\%) suggesting that ACC-producing MTB belonged to at least two genomic undescribed genera. As a result, based on the phylogeny inferred from the 16S rRNA gene sequences, these biomineralizing MTB formed a distinct new monophyletic clade within Rhodospirillaceae, related to a group composed of the Niveispirillum, Rhodocista, Nitrospirillum, Azospirillum, Desertibacter and Skermanella genera (Fig. 6a). However, the tree topology was not well statistically supported and could not entirely resolve the evolutionary relationships between Lake Pavin MTB and the closest Rhodospirillaceae genera. Indeed, the 16S rRNA sequences harboured too much interspecific polymorphism with important genetic saturation effects suggesting that the current Rhodospirillaceae family (NCBI taxonomy) may actually gather very divergent organisms. 

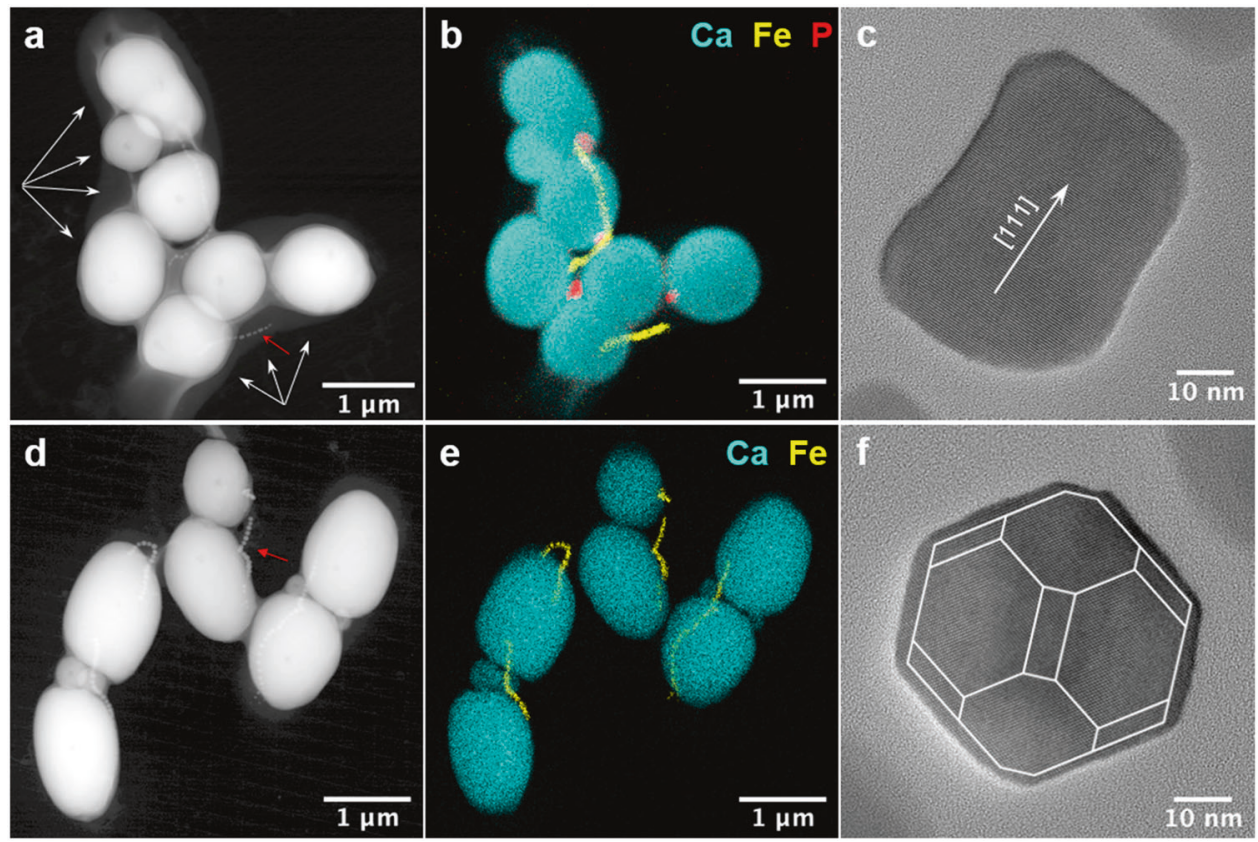

Fig. 3 Chemical identification of the mineral phase in the magnetosomes and the large inclusions of bacteria isolated from sediment samples. a STEM-HAADF image of two cells producing four (left cell) and three (right cell) large inclusions (indicated by white arrows). b Composite XEDS elemental mapping of calcium, iron and phosphorus. c High-resolution TEM image of a prismatic magnetosome (shown by a red arrow in panel a) elongated along the [111] axis. d STEM-HAADF image of three cells producing large and small inclusions). e composite XEDS elemental mapping of calcium and iron. $\mathbf{f}$ HR-TEM image of a cuboctahedral magnetosome (shown by a red arrow in panel d), an ideal model of a cuboctahedron with small $\{110\}$ faces is superimposed. Detailed information on the chemical and shape identification of the mineral phases present in these bacteria is given in Supplementary Information.
Fluorescent in situ hybridization (FISH) using specific fluorescently-labelled oligonucleotide probes and combining confocal microscopy with scanning electron microscopy observations further validated the ACC-producing MTB identity (Fig. 7). As expected from similar observations on ACC in cyanobacteria [22], the MTB ACC inclusions dissolved during the preparation of the FISH samples because of the detrimental impact of fixation followed by incubation in buffers undersaturated with ACC (Fig. 7e). A similar loss of ACC inclusions was observed in these bacteria when preparing ultrathin TEM sections following conventional ultramicrotomy protocols (Fig. S5a-c). In contrast, ACC inclusions were preserved by cryo-electron microscopy of vitreous sections (CEMOVIS) and showed the existence of a lipid bilayer-delimited intracellular compartment enclosing ACC (Fig. S5d-f).

The genome of the representative ACC-producing MTB clone CCP-1 was tentatively assembled. Single-cell sorting coupled with whole-genome amplification and sequencing allowed to assemble a partial genome sequence of $2.5 \mathrm{Mb}$, in which a single $16 \mathrm{~S}$ rRNA gene copy identical to the OTU1 sequence was detected. Completeness was estimated to be lower than $22 \%$, which was not satisfactory enough to get a reliable phylogeny reconstruction based on ribosomal proteins or to reconstruct full metabolic pathways. This result indicates that ACC-producing MTB may have an atypical large genome over $10 \mathrm{Mbp}$, compared to its closest relatives whose genomes size range between approximately 3 and $8 \mathrm{Mb}$ in average. Despite this low genome coverage, a full magnetosome gene cluster was retrieved from the longest contig of $72.5 \mathrm{kbp}$ using the BLASTP algorithm and the bank of mam sequences publicly available for all Alphaproteobacteria (RefSeq non-redundant proteins database). Its sequence was deposited in Genbank under the accession number MT411893. Indeed, up to 30 genes were unambiguously identified with a high sequence similarity with known magnetosome genes (See Table S1 and Fig. 6b). Comparative analysis of the magnetosome gene cluster (MGC) from representative magnetotactic Rhodospirillaceae showed the presence of the main operons described in Magnetospirillum species but with an atypical organization compared to both marine and freshwater strains (Fig. 6c). For example, the $\operatorname{mam} A B$ operon was complete with the exception of mamJ, which is a gene involved in ultrastructural organisation of the magnetosome chain specific to the Magnetospirillum genus. However, gene synteny was not conserved in the $\operatorname{mam} A B$ operon, just as for the mamXZ operon in which no $\operatorname{mam} Y$ was detected. Finally, the canonical form of the mamGFDC operon was not present. 
Fig. 4 Evidence of strontium and barium in the calciumrich inclusions. a STEM-

HAADF image of cells with calcium-rich inclusions, isolated from the sediment of Lake Pavin. b Composite XEDS elemental mapping of calcium, iron and phosphorus. $\mathbf{c}$ XEDS elemental spectrum of an inclusion showing the presence of calcium as well as traces of strontium and barium. Note that the coordinate axis is in logarithmic scale.
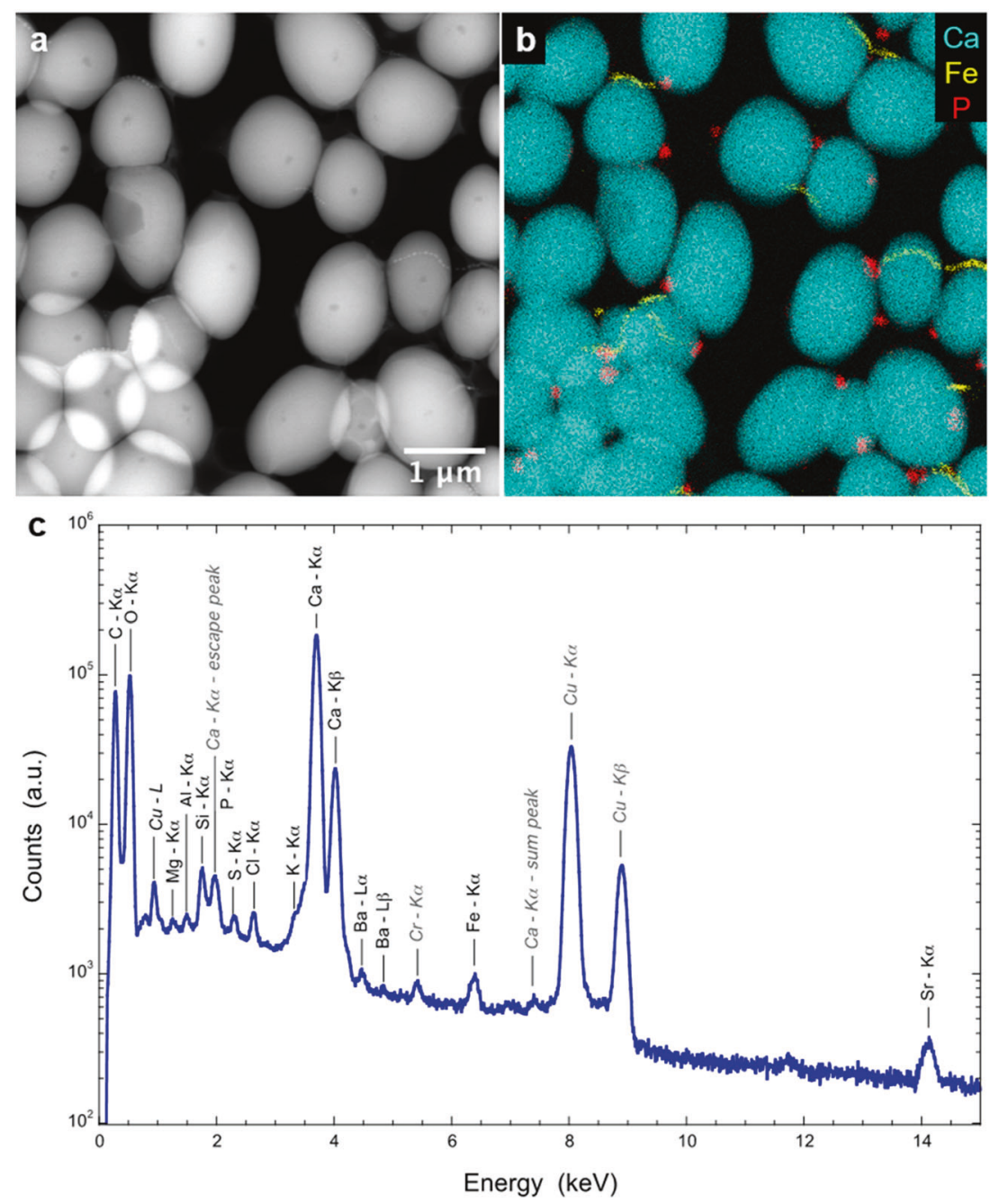

\section{Discussion}

The ability to mineralize calcium carbonates has been described in very few prokaryotic taxa so far and despite the tremendous importance that such a function may have had in the Earth's history, very little is known about its distribution in the tree of Bacteria, its genetic basis and its ecological role. This gap may be partially reduced by describing new organisms producing calcium carbonates in very divergent phyla with different ecological niches. Here, we not only described a bacterium able to perform two different types of biomineralization, but we also extended the record of microorganisms able to perform intracellular Ca-carbonate biomineralization from two to three farrelated groups of Bacteria: Gammaproteobacteria, Cyanobacteria and Alphaproteobacteria. The MTB performing both magnetic iron oxide and calcium carbonate biomineralization in the ferruginous Lake Pavin undoubtedly form a monophyletic group composed at least of one or two genera that are distinct from those currently described within the
Alphaproteobacteria. The majority of the phylogenetically closest genera, i.e. Niveispirillum, Rhodocista, Nitrospirillum, Azospirillum and Skermanella, includes species isolated from the rhizosphere or freshwater environments. None of the species from these genera has been reported to biomineralize ACC [58-62]. Most of these species are chemoorganoheterotrophic and aerobic, but some can also be anaerobically phototrophic. Future culture assays and genome sequencing will determine if ACC-accumulating MTB have similar metabolisms and will help resolving the ancestry of both biomineralization processes in Alphaproteobacteria.

MTB have often been used to illustrate how the cell functioning and compartmentalization can be complex in prokaryotes through the description of numerous morphotypes with diverse cell ultrastructures and physiologies in very chemically contrasted environments [63, 64]. Besides magnetosomes, other large inclusion bodies storing elemental sulphur, polyphosphates, or polyhydroxybutyrates (PHB) have been regularly observed in MTB [46, 65-73]. 
Fig. 5 STXM analyses measured at the $\mathrm{C}$ K-edge on intracellular inclusions of magnetotactic bacteria isolated from Lake Pavin. a Bacterial cell isolated from the water column. From left to right: STXM image at $320 \mathrm{eV}$; Map of two spectroscopically different compounds derived from the analysis of a hyperspectral image: an ACC-like compound (red) and an organic, cell-like compound (blue); XANES spectrum at the $\mathrm{C} \mathrm{K}$-edge of the ACC-like compound and of a reference synthetic ACC sample. Y-axis shows optical density (OD) values. Peaks 1, 2 and 3 seen in both reference and MTB inclusions are located at 290.3, 296.2 and $301.6 \mathrm{eV}$. b Bacterial cell isolated from the sediment. From left to right: same as in panel a. a
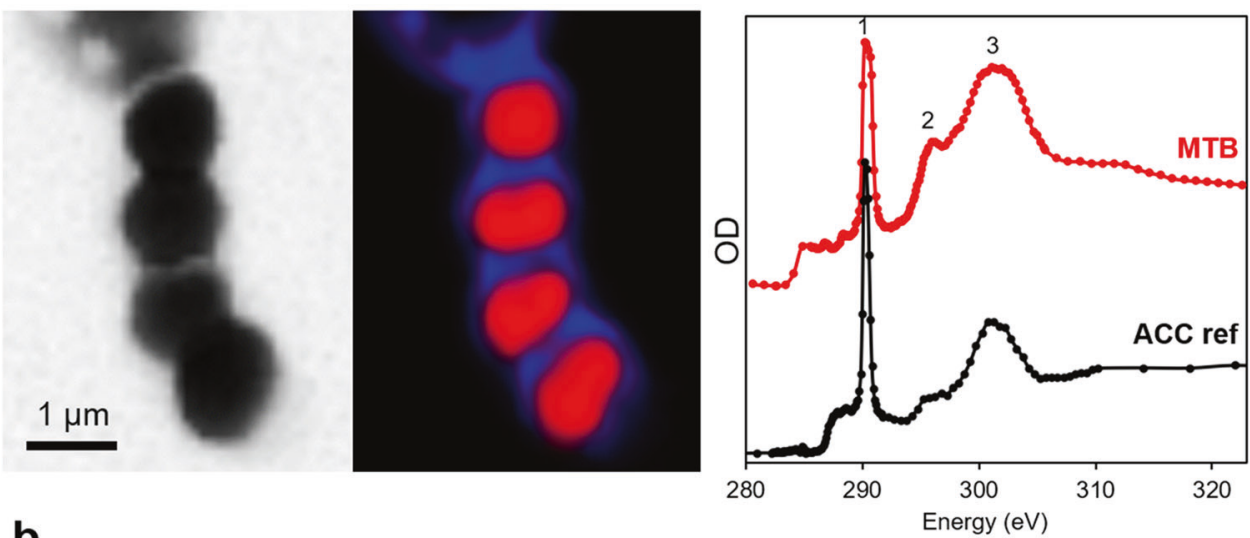

b

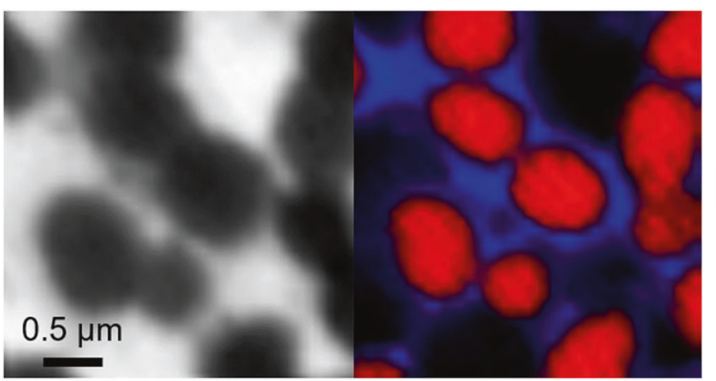

Here, we extend the range of inclusions that MTB may form and give insights into the ultrastructure, chemistry and formation of ACC inclusions during the cell cycle. TEM analyses showed that the inclusions were amorphous and CEMOVIS confirmed the presence of a surrounding membrane. Interestingly, XEDS analyses showed the presence of $\mathrm{Sr}$ and $\mathrm{Ba}$ in the ACC granules. The accumulation of the alkaline earth elements such as $\mathrm{Ca}, \mathrm{Sr}$ and $\mathrm{Ba}$ at a high level has been demonstrated for the ACC-biomineralizing cyanobacterium Gloeomargarita lithophora [74]. For this reason, it has been suggested that these prokaryotes could be used to remediate pollutions by alkaline earth elements [26]. If such high accumulation abilities were proven for these ACC-producing MTB, they may similarly be suitable for designing new remediation strategies or other applications under physicochemical conditions different from those allowing the use of cyanobacteria [75]. In the light of our data, it is still unclear how ACC-containing vesicles form and how cytosolic conditions initiate the formation of ACC. However, similarly to what has been shown for three strains of cyanobacteria [76] and for Achromatium [12], we showed that Alphaproteobacteria MTB also form Cacarbonates intracellularly in solutions undersaturated with respect to ACC phases. In other words, these extracellular conditions are thermodynamically unfavourable to mineral precipitation, which indicates that $\mathrm{ACC}$ formation in $\mathrm{MTB}$ is an active process and costs energy to the cell to maintain an intracellular environment supersaturated with ACC, most likely within the membrane-enclosed compartment observed by CEMOVIS.

TEM observations provided additional information on the biogenesis of these inclusions. During cell division, each daughter cell systematically harboured one significantly smaller ACC inclusion in the vicinity of the septum, that remained at one cell pole once cells detached. Interestingly, a similar connection between ACC biomineralization and cell division was observed in cyanobacteria species belonging to the Thermosynechococcus elongatus BP-1 clade [23]. These observations raise questions about the formation, inheritance and maintenance of the polarity of the cells, that of the the magnetosome chain and ACC inclusions over generations. Indeed, it is known that magnetosomes formation is a complex process where chains of magnetosome particles are concatenated, positioned and segregated by a multi-partite cytoskeletal network, called the magnetoskeleton [77, 78]. The atypical MGC found in the genome of ACC-producing MTB could be an indication of a specific adaptation of these bacteria to produce straight magnetosome chains in such a crowded cytoplasm. Monotrichously flagellated MTB developed specific dividing strategies or sensory apparatus to keep a sustainable magnetotaxis and produce two daughter cells with a similar 
a

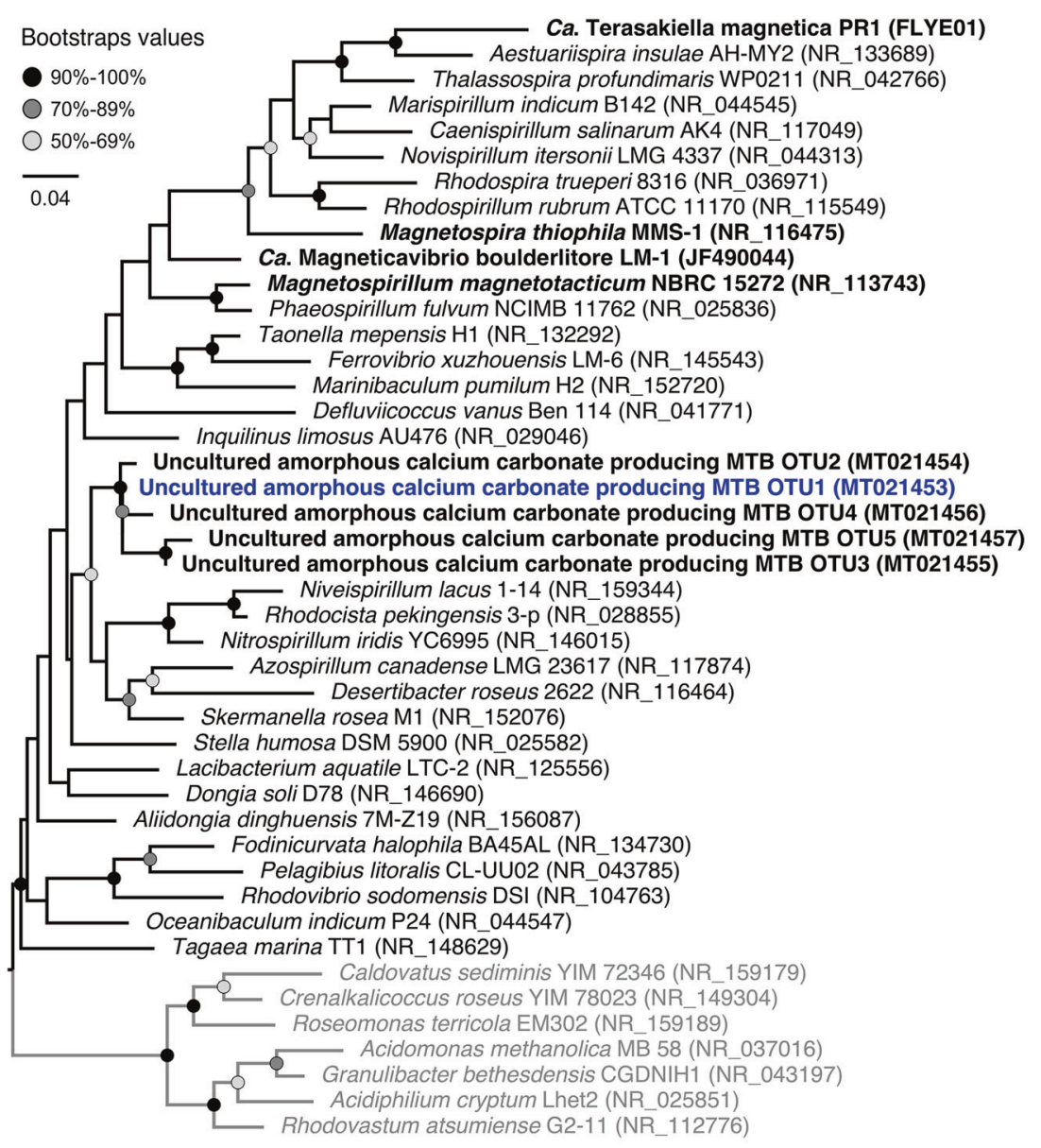

b mamGFDC / mms 6/36/48 / mamAB / mamZXY / feoABm
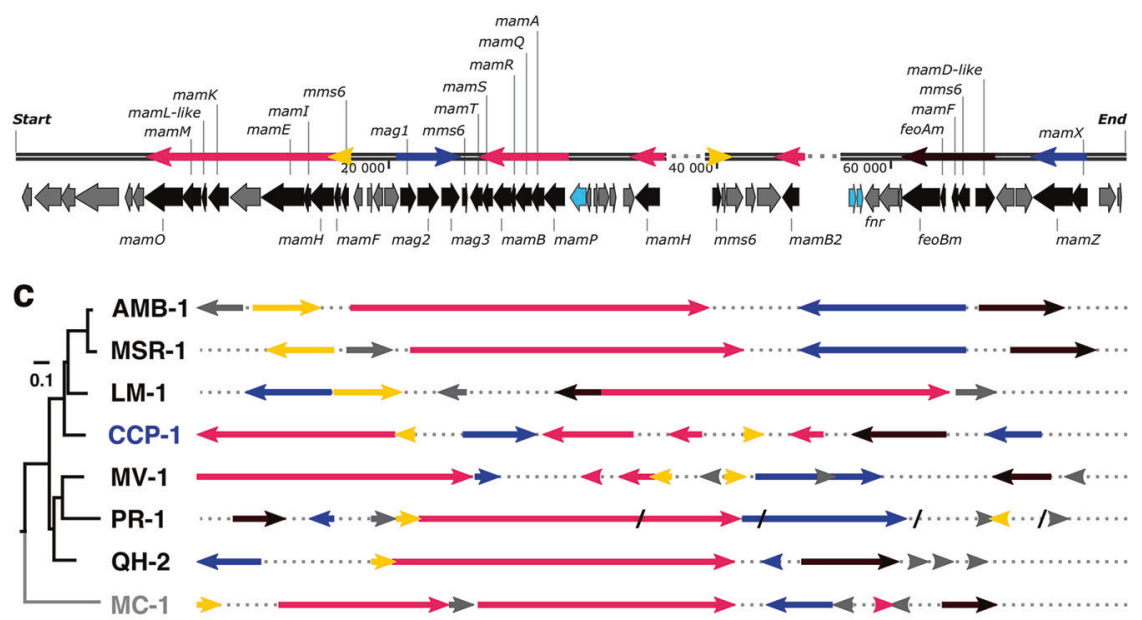

magnetic polarity, i.e. swimming in the same direction along magnetic field lines [79]. Here, in ACC-producing Alphaproteobacteria, the flagellum was always observed at the oldest pole where the largest and likely oldest ACC inclusion stands. This suggests that similarly to Magnetovibrio blakemorei strain MV-1, they divide according to a scheme whereby the newly synthesized flagellum emerges from the mother pole initially devoid of a flagellum [79]. This represents a most common dividing scheme similar to that observed in Caulobacter crescentus [80]. In strain MV1 , all daughter cells swim in the same direction (northseeking), so it was suggested that the flagellum pushes the 
4 Fig. 6 Phylogenetic and magnetosome gene cluster (MGC) analyses of ACC-producing MTB isolated from sediment samples of Lake Pavin. a Maximum-likelihood tree of the Rhodospirillaceae family (NCBI taxonomy) based on the 16S rRNA gene and rooted with representative members of the Acetobacteraceae (grey group). Branch length represents the number of substitutions per site. Bootstrap values were estimated with a non-parametric bootstrap approach and 500 replicates. Representative MTB species and ACC producing MTB are in bold. The OTU to which the clone CCP- 1 was affiliated is in dark blue. b MGC organization of the ACC-producing MTB clone CCP-1 representing OTU1. All genes homologous to any known magnetosome gene are coloured in black. Any gene with unknown function conserved in the vicinity of other MGCs is highlighted in light blue. The map of the contig was drawn to scale and its sequences can be retrieved under the Genbank accession number MT411893. Main operons organisation described in Magnetospirillum species [5] are symbolized with arrows above the map. $\mathbf{c}$ Comparative analysis of the MGCs from the ACC producing clone CCP-1 and different representative magnetotactic Rhodospirillaceae strains previously reviewed in detail in Monteil et al. [90]. (AMB-1: Magnetospirillum magneticum, MSR-1: Magnetospirillum gryphiswaldense, LM-1: Ca. Magneticavibrio boulderlitore, MV-1: Magnetovibrio blakemorei, PR1: Ca. Terasakiella magnetica, QH-2: Ca. Magnetospira sp.). MGCs were organized according to the phylogeny based on MTB 16S rRNA gene sequences, rooted with the sequence of Magnetococcus marinus strain MC-1 (NR_074371.1). The arrows symbolize operons described by Uebe and Schüler [5]; they were drawn to scale and the direction symbolizes the relative position of genes within the operons in respect to that described in species of the Magnetospirillum genus. Dotted lines symbolize continuous genomic regions and were not drawn to scale, while slashes represent contigs edges.

cell body for one half of the population while pulling it for the other half of the population. In contrast, magnetic enrichments of ACC-producing MTB populations collected from the shore of Lake Pavin revealed a similar fraction of south-seeking and north-seeking cells. This observation suggests that for these MTB, two daughter cells swim in opposite direction along magnetic field lines: the cell inheriting the ancient flagellum will keep swimming in the same direction than the mother cell, while the cell inheriting the newly synthetized flagellum will swim toward the opposite direction. This observation is of ecological significance since it means that these population of MTB use the magnetic field only as an axis of motility. Their chemotactic machinery is then responsible for their stabilization in their optimal habitat [81].

Magnetotaxis is not the only strategy developed by microorganisms to facilitate their vertical motility in the water column. For instance, some microorganisms living in anoxic environments developed a negative phototactic response to the shorter wavelengths of visible light that penetrate the deepest in the water column [82]. This behaviour, allowed by specific photoreceptors, drives these microorganisms toward and into the anaerobic zone of aquatic habitats where they are found at their highest abundance. Similarly, gas vesicles formed by some organisms are used as positive or negative buoyant to perform vertical migrations in the water column [83]. For some cyanobacteria, gas vesicles increase their residence time in the euphotic zone and are responsible for surface waterblooms [84]. May ACC inclusions contribute to the vertical motility of these MTB in the water column? The role of Cacarbonate inclusions in the vertical motility of bacteria has been postulated for Achromatium as well as cyanobacteria [13, 17, 19, 29]. Interestingly, the ACC-producing MTB described here had a magnetotactic behaviour different from that usually observed for environmental magneticallyresponsive microorganisms. Indeed, they did not aggregate at the edge of hanging drops after their magnetic enrichment from aquatic samples. Instead, cells settled down at the bottom of the drops, swimming along the magnetic field lines applied and displaying a back and reverse motility. Similarly, when deposited between a microscope slide and a coverslip, cells were systematically observed swimming in the deepest part of the preparation. We showed that ACC inclusions could occupy up to twothirds of the cytoplasm, representing a considerable increase of cell negative buoyancy. This indicates the potential of ACC to serve as ballasts and could represent an adaptation to a benthic lifestyle, cells adjusting their vertical positioning using their flagellum. It is possible that this process functions in coordination with magnetotaxis where the axis of motility and orientation of the cell would be directed by the magnetosomes chain while the direction of motility would be given by gravitaxis associated with ACC inclusions.

This unique behaviour, the potential ACC loss upon standard TEM sample preparation and the difficulty to observe their magnetosomes due to the electron dense ACC inclusions filling the cytoplasm, could explain why these microorganisms have been overlooked so far. In some samples, these bacteria could reach a cell density above $10^{5}$ cells $/ \mathrm{mL}$ but yet remained invisible when standard protocols were used to quantify MTB [63]. Recently, it was shown that the adaptation of new protocols for the sampling, magnetic enrichment and observation allowed the discovery of new magnetically-responsive microorganisms [85-87]. It is thus important to permanently reassess how to observe magnetotactic organisms to unravel their whole diversity. Here, the new ACC-accumulating microorganisms were discovered owing to the observation of an unusual magnetotactic behaviour that gives the opportunity to concentrate rare organisms from complex communities. This double biomineralization may be more widespread than we currently think. Indeed, some $\mathrm{Ba}$ - and $\mathrm{Ca}$-rich inclusions were observed in environmental MTB collected in the Seine River (France) [88] and another study reported the presence of Ca-rich granules occupying most of the intracellular volume of the giant freshwater magnetotactic rod-shaped strain GRS-1, affiliated with the Gammaproteobacteria [89], 

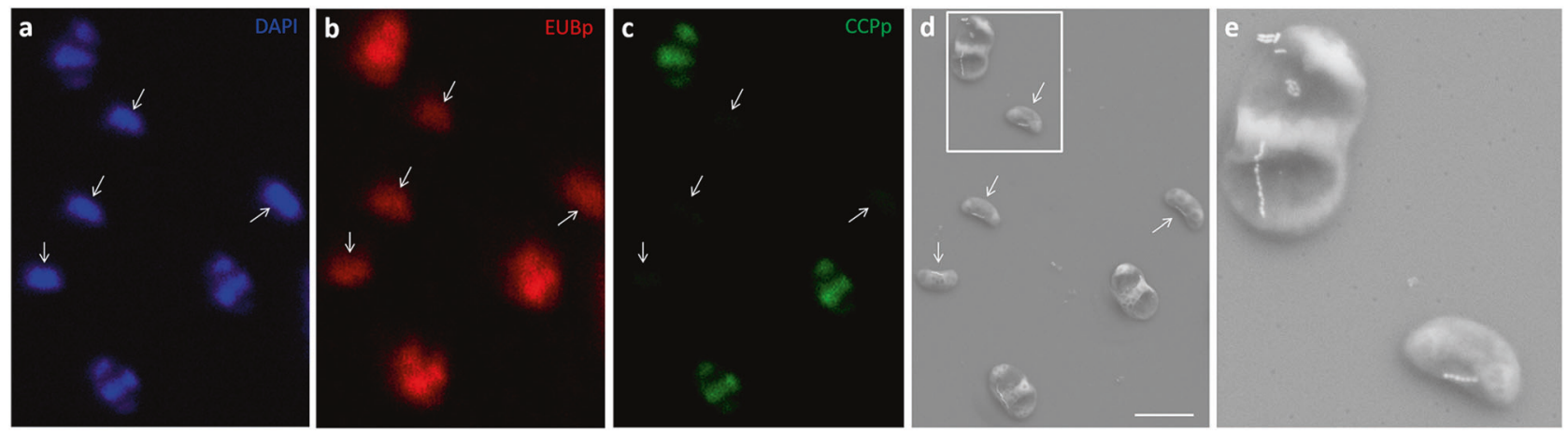

Fig. 7 Fluorescence in situ hybridization (FISH) of magnetically concentrated MTB from the sediments of Lake Pavin. The specific oligonucleotide rRNA probe (CCPp) was used to authenticate the $16 \mathrm{~S}$ rRNA gene sequence of MTB with $\mathrm{CaCO}_{3}$ inclusions. a Fluorescence microscope image of three rods with large inclusions and four smaller vibrio (shown by white arrows) stained with 4',6-diamidino-2-phenylindole (DAPI). b Fluorescence microscope image of the same cells hybridized with the Bacteria specific probe Eubp. Note that both cell morphotypes fluoresce with this probe. c Fluorescence microscope image of the same cells hybridized with the CCP-specific probe. Only cells with large inclusions fluoresce with this probe. d Scanning electron microscope (SEM) image of the same cells showing their ultrastructure and magnetosomes. White frame indicates the position of the SEM image in panel e. Scale bar represents $2 \mu \mathrm{m}$. although none of these studies confirmed or infirmed that these inclusions are made of amorphous or crystalline carbonates. Presuming that the above-mentioned inclusions were amorphous carbonate phases, all these observations suggest the phylogenetic diversity of ACC-producing MTB may be even higher than what is reported here. Indeed, although strain GRS-1 and Achromatium belong to the same order, i.e. Thiotrichales, both strains remain phylogenetically distant [89]. Besides finding the origin of such processes, future comparative genomics and molecular phylogenies will infer the ancestry and evolutionary forces associated to their diversification.

Acknowledgements This work was supported by the CNRS: "Programme national Ecosphère Continentale et Côtière (EC2CO)" (BACCARAT2 $-\mathrm{N}^{\circ} 13068$ ) and the French National Research Agency (SIGMAG: ANR-18-CE31-0003 and PHOSTORE: ANR-19-CE010005-02). CCB was supported by the Frontières de l'Innovation en Recherche et Éducation (FIRE) Ph.D. programme from the Centre de Recherches Interdisciplinaires (CRI). Support for the confocal microscope was provided by the Région Provence Alpes Côte d'Azur, Conseil Général des Bouches du Rhône, French Ministry of Research, CNRS and Commissariat à l'Energie Atomique et aux Energies Alternatives. We acknowledge the Institut de Radioprotection et de Sûreté Nucléaire (IRSN) at CEA Cadarache for the access of the transmission electron microscope Tecnai $G^{2}$ BioTWIN. We are grateful to the INRA MIGALE bioinformatics platform (http://migale. jouy.inra.fr) for providing computational resources. We thank Stefan Stanescu and Rachid Belkhou for user support on the HERMES STXM beamline at Synchrotron SOLEIL, Fériel Skouri-Panet and Cynthia Travert for user support on the IMPMC Biology facility, JeanMichel Guigner for user support on the IMPMC TEM facility and Imène Esteve, Béatrice Doisneau and Stéphanie Delbrel for user support on the IMPMC SEM facility. We are grateful to the genomic platform at the Institut de Microbiologie de la Méditerranée (IMM) and to Yann Denis for helpful advices. We thank Alexis Canette from the Service de Microscopie Electronique at the IBPS for his help in CEMOVIS sample preparation. We thank Maria Pilar Asta and
Alejandro Fernandez-Martinez from ISTerre, University Grenoble Alpes, for providing a reference ACC sample.

\section{Compliance with ethical standards}

Conflict of interest The authors declare that they have no conflict of interest.

Publisher's note Springer Nature remains neutral with regard to jurisdictional claims in published maps and institutional affiliations.

\section{References}

1. Weiner S, Dove PM. An overview of biomineralization processes and the problem of the vital effect. Rev Miner Geochem. 2003;54:1-29.

2. Benzerara K, Miot J, Morin G, Ona-Nguema G, Skouri-Panet F, Férard C. Significance, mechanisms and environmental implications of microbial biomineralization. Comptes Rendus Geosci. 2011;343:160-7.

3. Lowenstam HA. Minerals formed by organisms. Science. 1981;211:1126-31.

4. Blakemore R. Magnetotactic bacteria. Science. 1975;190:377-9.

5. Uebe R, Schüler D. Magnetosome biogenesis in magnetotactic bacteria. Nat Rev Microbiol. 2016;14:621-37.

6. Grant CR, Wan J, Komeili A. Organelle formation in bacteria and archaea. Annu Rev Cell Dev Biol. 2018;34:217-38.

7. Schewiakoff W. Über einen neuen bacterienahnlichen organismus des Süsswassers. Heidelb Habilit. 1893;1-38.

8. West GS, Griffiths BM. The lime-sulphur bacteria of the genus hillhousia. Ann Bot. 1913;os-27:83-91.

9. Head IM, Gray ND, Clarke KJ, Pickup RW, Jones JG. The phylogenetic position and ultrastructure of the uncultured bacterium Achromatium oxaliferum. Microbiol Read Engl. 1996;142(Pt 9):2341-54.

10. Salman V, Yang T, Berben T, Klein F, Angert E, Teske A. Calcite-accumulating large sulfur bacteria of the genus Achromatium in Sippewissett Salt Marsh. ISME J. 2015;9:2503-14.

11. Mansor M, Hamilton TL, Fantle MS, Macalady J. Metabolic diversity and ecological niches of Achromatium populations 
revealed with single-cell genomic sequencing. Front Microbiol. 2015;6:822.

12. Gray N, Head I. The family achromatiaceae. In: Rosenberg E, DeLong EF, Lory S, Stackebrandt E, Thompson F, editors. The Prokaryotes: Gammaproteobacteria. Berlin, Heidelberg: Springer; 2014. p. 1-14.

13. Head IM, Gray ND, Howarth R, Pickup RW, Clarke KJ, Jones JG. Achromatium oxaliferum Understanding the Unmistakable. In: Schink B, editor. Advances in microbial ecology. Boston, MA: Springer US; 2000. p. 1-40.

14. Babenzien H-D, Sass H. The sediment-water interface-habitat of the unusual bacterium Achromatium oxaliferum. Adv Limnol. 1996;48:247-51.

15. Gray ND, Pickup RW, Jones JG, Head IM. Ecophysiological evidence that achromatium oxaliferum is responsible for the oxidation of reduced sulfur species to sulfate in a freshwater sediment. Appl Environ Microbiol. 1997;63:1905-10.

16. Gray ND, Howarth R, Pickup RW, Jones JG, Head IM. Substrate uptake by uncultured bacteria from the genus Achromatium determined by microautoradiography. Appl Environ Microbiol. 1999;65:5100-6.

17. Babenzien H-D. Achromatium oxaliferum and its ecological niche. Zentralblatt Für Mikrobiol. 1991;146:41-49.

18. Gray ND, Comaskey D, Miskin IP, Pickup RW, Suzuki K, Head IM. Adaptation of sympatric Achromatium spp. to different redox conditions as a mechanism for coexistence of functionally similar sulphur bacteria. Environ Microbiol. 2004;6:669-77.

19. Couradeau E, Benzerara K, Gérard E, Moreira D, Bernard S, Brown GE, et al. An early-branching microbialite cyanobacterium forms intracellular carbonates. Science. 2012;336:459-62.

20. Cam N, Benzerara K, Georgelin T, Jaber M, Lambert J-F, Poinsot M, et al. Selective Uptake of Alkaline Earth Metals by Cyanobacteria Forming Intracellular Carbonates. Environ Sci Technol. 2016;50:11654-62.

21. Blondeau M, Sachse M, Boulogne C, Gillet C, Guigner J-M, Skouri-Panet F, et al. Amorphous calcium carbonate granules form within an intracellular compartment in calcifying cyanobacteria. Front Microbiol. 2018;9:1768.

22. Li J, Margaret Oliver I, Cam N, Boudier T, Blondeau M, Leroy E, et al. Biomineralization patterns of intracellular carbonatogenesis in cyanobacteria: molecular hypotheses. Minerals. 2016;6:10.

23. Benzerara K, Skouri-Panet F, Li J, Férard C, Gugger M, Laurent $\mathrm{T}$, et al. Intracellular Ca-carbonate biomineralization is widespread in cyanobacteria. Proc Natl Acad Sci USA. 2014;111:10933-8.

24. Bradley JA, Daille LK, Trivedi CB, Bojanowski CL, Stamps BW, Stevenson BS, et al. Carbonate-rich dendrolitic cones: insights into a modern analog for incipient microbialite formation, Little Hot Creek, Long Valley Caldera, California. NPJ Biofilms Microbiomes. 2017;3:32.

25. Moreira D, Tavera R, Benzerara K, Skouri-Panet F, Couradeau E, Gérard E, et al. Description of Gloeomargarita lithophora gen. nov., sp. nov., a thylakoid-bearing, basal-branching cyanobacterium with intracellular carbonates, and proposal for Gloeomargaritales ord. nov. Int J Syst Evol Microbiol. 2017;67:653-8.

26. Mehta N, Benzerara K, Kocar BD, Chapon V. Sequestration of radionuclides radium-226 and strontium-90 by cyanobacteria forming intracellular calcium carbonates. Environ Sci Technol. 2019;53:12639-47.

27. Ponce-Toledo RI, Deschamps P, López-García P, Zivanovic Y, Benzerara K, Moreira D. An early-branching freshwater cyanobacterium at the origin of plastids. Curr Biol CB. 2017;27:386-91.

28. la Rivière JWM, Schmidt K. Morphologically Conspicuous Sulfur-Oxidizing Eubacteria. In: Starr MP, Stolp H, Trüper HG, Balows A, Schlegel HG, editors. The prokaryotes: a handbook on habitats, isolation, and identification of bacteria. Berlin Heidelberg: Springer; 1981. p. 1037-48.
29. Gray ND. The unique role of intracellular calcification in the genus achromatium. In: Shively JM, editor. Inclusions in prokaryotes. Berlin, Heidelberg: Springer; 2006. p. 299-309.

30. Miot J, Jezequel D, Benzerara K, Cordier L, Rivas-Lamelo S, Skouri-Panet F, et al. Mineralogical diversity in lake pavin: connections with water column chemistry and biomineralization processes. Minerals. 2016;6:UNSP 24.

31. Podda F, Michard G. Mesure colorimétrique de l'alcalinité. Comptes Rendus Acad Sci - Sér II. 1994;319:651-7.

32. Sarazin G, Michard G, Prevot F. A rapid and accurate spectroscopic method for alkalinity measurements in sea water samples. Water Res. 1999;33:290-4.

33. Zeyen N, Daval D, Lopez-Garcia P, Moreira D, Gaillardet J, Benzerara K. Geochemical conditions allowing the formation of modern lacustrine microbialites. Procedia Earth Planet Sci. 2017;17:380-3.

34. Purgstaller B, Goetschl KE, Mavromatis V, Dietzel M. Solubility investigations in the amorphous calcium magnesium carbonate system. CrystEngComm. 2018;21:155-64.

35. Schüler D. The biomineralization of magnetosomes in Magnetospirillum gryphiswaldense. Int Microbiol J Span Soc Microbiol. 2002;5:209-14.

36. Lane DJ. 16S/23S sequencing. In: Stackebrandt E, Goodfellow M, editor. Nucleic acid techniques in bacterial systematics. New York: John Wiley \& Sons; 1991. p. 115-75.

37. Altschul SF, Madden TL, Schaffer AA, Zhang JH, Zhang Z, Miller W, et al. Gapped BLAST and PSI-BLAST: a new generation of protein database search programs. Nucleic Acids Res. 1997;25:3389-402.

38. Edgar RC. UCHIME2: improved chimera prediction for amplicon sequencing. bioRxiv 2016. https://www.biorxiv.org/content/10. 1101/074252v1.

39. Gascuel O. BIONJ: an improved version of the NJ algorithm based on a simple model of sequence data. Mol Biol Evol. 1997;14:685-95.

40. Katoh K, Standley DM. MAFFT multiple sequence alignment software version 7: improvements in performance and usability. Mol Biol Evol. 2013;30:772-80.

41. Talavera G, Castresana J. Improvement of phylogenies after removing divergent and ambiguously aligned blocks from protein sequence alignments. Syst Biol. 2007;56:564-77.

42. Nguyen L-T, Schmidt HA, von Haeseler A, Minh BQ. IQ-TREE: a fast and effective stochastic algorithm for estimating maximumlikelihood phylogenies. Mol Biol Evol. 2015;32:268-74.

43. Kalyaanamoorthy S, Minh BQ, Wong TKF, von Haeseler A, Jermiin LS. ModelFinder: fast model selection for accurate phylogenetic estimates. Nat Methods. 2017;14:587-9.

44. Pernthaler J, Glockner FO, Schonhuber W, Amann R. Fluorescence in situ hybridization (FISH) with rRNA-targeted oligonucleotide probes. Methods Microbiol Vol 30. 2001; 30:207-26.

45. Cole JR, Chai B, Marsh TL, Farris RJ, Wang Q, Kulam SA, et al. The Ribosomal Database Project (RDP-II): previewing a new autoaligner that allows regular updates and the new prokaryotic taxonomy. Nucleic Acids Res. 2003;31:442-3.

46. Rivas-Lamelo S, Benzerara K, Lefèvre CT, Jézéquel D, Menguy $\mathrm{N}$, Viollier E, et al. Magnetotactic bacteria as a new model for $\mathrm{P}$ sequestration in the ferruginous Lake Pavin. Geochem Perspect Lett. 2017;5:35-41.

47. Bolger AM, Lohse M, Usadel B. Trimmomatic: a flexible trimmer for Illumina sequence data. Bioinforma Oxf Engl. 2014;30:2114-20.

48. Seemann T. Prokka: rapid prokaryotic genome annotation. Bioinformatics. 2014;30:2068-9.

49. Parks DH, Imelfort M, Skennerton CT, Hugenholtz P, Tyson GW. CheckM: assessing the quality of microbial genomes recovered 
from isolates, single cells, and metagenomes. Genome Res. 2015;25:1043-55.

50. Belkhou R, Stanescu S, Swaraj S, Besson A, Ledoux M, Hajlaoui M, et al. HERMES: a soft X-ray beamline dedicated to X-ray microscopy. J Synchrotron Radiat. 2015;22:968-79.

51. Swaraj S, Belkhou R, Stanescu S, Rioult M, Besson A, Hitchcock AP. Performance of the HERMES beamline at the carbon K-edge. J Phys Conf Ser. 2017;849:012046.

52. Le Nagard L, Zhu X, Yuan H, Benzerara K, Bazylinski DA, Fradin $\mathrm{C}$, et al. Magnetite magnetosome biomineralization in Magnetospirillum magneticum strain AMB-1: A time course study. Chem Geol. 2019;530:119348.

53. Cosmidis J, Benzerara K. Soft x-ray scanning transmission spectro-microscopy. In: Elaine DiMasi, Laurie B. Gower, editors. Biomineralization sourcebook: characterization of biominerals and biomimetic materials. CRC Press; 2014.

54. Lefèvre CT. Genomic insights into the early-diverging magnetotactic bacteria. Environ Microbiol. 2016;18:1-3.

55. Benzerara K, Yoon TH, Tyliszczak T, Constantz B, Spormann AM, Brown GE. Scanning transmission X-ray microscopy study of microbial calcification. Geobiology. 2004;2:249-59.

56. Michard G, Viollier E, Jézéquel D, Sarazin G. Geochemical study of a crater lake: Pavin Lake, France - Identification, location and quantification of the chemical reactions in the lake. Chem Geol. 1994;115:103-15.

57. Konstantinidis KT, Rosselló-Móra R, Amann R. Uncultivated microbes in need of their own taxonomy. ISME J. 2017;11: 2399-406.

58. Cai H, Wang Y, Xu H, Yan Z, Jia B, Majid Maszenan A, et al. Niveispirillum cyanobacteriorum sp. nov., a nitrogen-fixing bacterium isolated from cyanobacterial aggregates in a eutrophic lake. Int J Syst Evol Microbiol. 2015;65:2537-41.

59. Zhang D, Yang H, Zhang W, Huang Z, Liu S-J. Rhodocista pekingensis sp. nov., a cyst-forming phototrophic bacterium from a municipal wastewater treatment plant. Int J Syst Evol Microbiol. 2003;53:1111-4.

60. Chung EJ, Park TS, Kim KH, Jeon CO, Lee H-I, Chang W-S, et al. Nitrospirillum irinus sp. nov., a diazotrophic bacterium isolated from the rhizosphere soil of Iris and emended description of the genus Nitrospirillum. Antonie Van Leeuwenhoek. 2015;108:721-9.

61. Bashan Y, Holguin G, de-Bashan LE. Azospirillum-plant relationships: physiological, molecular, agricultural, and environmental advances (1997-2003). Can J Microbiol. 2004;50:521-77.

62. Guo Q, Zhou Z, Zhang L, Zhang C, Chen M, Wang B, et al. Skermanella pratensis sp. nov., isolated from meadow soil, and emended description of the genus Skermanella. Int J Syst Evol Microbiol. 2020;70:1605-9.

63. Lefèvre CT, Bazylinski DA. Ecology, diversity, and evolution of magnetotactic bacteria. Microbiol Mol Biol Rev. 2013; 77:497-526.

64. Lin W, Bazylinski DA, Xiao T, Wu L-F, Pan Y. Life with compass: diversity and biogeography of magnetotactic bacteria. Environ Microbiol. 2014;16:2646-58.

65. Bazylinski DA, Dean AJ, Williams TJ, Long LK, Middleton SL, Dubbels BL. Chemolithoautotrophy in the marine, magnetotactic bacterial strains MV-1 and MV-2. Arch Microbiol. 2004;182: 373-87.

66. Schultheiss D, Handrick R, Jendrossek D, Hanzlik M, Schüler D. The presumptive magnetosome protein Mms16 is a poly(3hydroxybutyrate) granule-bound protein (phasin) in Magnetospirillum gryphiswaldense. J Bacteriol. 2005;187:2416-25.

67. Lefèvre CT, Bernadac A, Yu-Zhang K, Pradel N, Wu L-F. Isolation and characterization of a magnetotactic bacterial culture from the Mediterranean Sea. Environ Microbiol. 2009;11: 1646-57.
68. Qian X-X, Liu J, Menguy N, Li J, Alberto F, Teng Z, et al. Identification of novel species of marine magnetotactic bacteria affiliated with Nitrospirae phylum. Environ Microbiol Rep. 2019;11:330-7.

69. Lefèvre CT, Frankel RB, Abreu F, Lins U, Bazylinski DA. Culture-independent characterization of a novel, uncultivated magnetotactic member of the Nitrospirae phylum. Environ Microbiol. 2011;13:538-49.

70. Cox BL, Popa R, Bazylinski DA, Lanoil B, Douglas S, Belz A, et al. Organization and elemental analysis of P-, S-, and Fe-rich inclusions in a population of freshwater magnetococci. Geomicrobiol J. 2002;19:387-406.

71. Byrne ME, Ball DA, Guerquin-Kern J-L, Rouiller I, Wu T-D, Downing KH, et al. Desulfovibrio magneticus RS-1 contains an iron- and phosphorus-rich organelle distinct from its bullet-shaped magnetosomes. Proc Natl Acad Sci USA. 2010;107:12263-8.

72. Keim CN, Solórzano G, Farina M, Lins U. Intracellular inclusions of uncultured magnetotactic bacteria. Int Microbiol J Span Soc Microbiol. 2005;8:111-7.

73. Schulz-Vogt HN, Pollehne F, Jürgens K, Arz HW, Beier S, Bahlo $\mathrm{R}$, et al. Effect of large magnetotactic bacteria with polyphosphate inclusions on the phosphate profile of the suboxic zone in the Black Sea. ISME J. 2019;13:1198-208.

74. Blondeau M, Benzerara K, Ferard C, Guigner J-M, Poinsot M, Coutaud M, et al. Impact of the cyanobacterium Gloeomargarita lithophora on the geochemical cycles of $\mathrm{Sr}$ and $\mathrm{Ba}$. Chem Geol. 2018;483:88-97.

75. Anbu P, Kang C-H, Shin Y-J, So J-S. Formations of calcium carbonate minerals by bacteria and its multiple applications. Springerplus. 2016;5:250.

76. Cam N, Benzerara K, Georgelin T, Jaber M, Lambert J-F, Poinsot $\mathrm{M}$, et al. Cyanobacterial formation of intracellular Ca-carbonates in undersaturated solutions. Geobiology. 2018;16:49-61.

77. Toro-Nahuelpan M, Müller FD, Klumpp S, Plitzko JM, Bramkamp M, Schüler D. Segregation of prokaryotic magnetosomes organelles is driven by treadmilling of a dynamic actin-like MamK filament. BMC Biol. 2016;14:88.

78. Toro-Nahuelpan M, Giacomelli G, Raschdorf O, Borg S, Plitzko JM, Bramkamp M, et al. MamY is a membrane-bound protein that aligns magnetosomes and the motility axis of helical magnetotactic bacteria. Nat Microbiol. 2019;4:1978-89.

79. Lefèvre CT, Bennet M, Klumpp S, Faivre D. Positioning the flagellum at the center of a dividing cell to combine bacterial division with magnetic polarity. mBio. 2015;6:e02286.

80. Judd EM, Ryan KR, Moerner WE, Shapiro L, McAdams HH. Fluorescence bleaching reveals asymmetric compartment formation prior to cell division in Caulobacter. Proc Natl Acad Sci USA. 2003;100:8235-40.

81. Klumpp S, Lefèvre CT, Bennet M, Faivre D. Swimming with magnets: From biological organisms to synthetic devices. Phys Rep. 2019;789:1-54.

82. Lefèvre CT, Abreu F, Lins U, Bazylinski DA. Nonmagnetotactic multicellular prokaryotes from low-saline, nonmarine aquatic environments and their unusual negative phototactic behavior. Appl Environ Microbiol. 2010;76:3220-7.

83. Walsby AE. Gas vesicles. Microbiol Rev. 1994;58:94-144.

84. Walsby A. The properties and buoyancy-providing role of gas vacuoles in trichodesmium ehrenberg. $\mathrm{Br}$ Phycol J. 1978;13:103-16.

85. Monteil CL, Menguy N, Prévéral S, Warren A, Pignol D, Lefèvre CT. Accumulation and dissolution of magnetite crystals in a magnetically responsive ciliate. Appl Environ Microbiol. 2018;84: e02865-17.

86. Monteil CL, Vallenet D, Menguy N, Benzerara K, Barbe V, Fouteau $\mathrm{S}$, et al. Ectosymbiotic bacteria at the origin of magnetoreception in a marine protist. Nat Microbiol. 2019;4:1088-95. 
87. Leão P, Nagard LL, Yuan H, Cypriano J, Silva-Neto ID, Bazylinski DA, et al. Magnetosome magnetite biomineralization in a flagellated protist: evidence for an early evolutionary origin for magnetoreception in eukaryotes. Environ Microbiol. 2020;22: 1495-506.

88. Isambert A, Menguy N, Larquet E, Guyot F, Valet J-P. Transmission electron microscopy study of magnetites in a freshwater population of magnetotactic bacteria. Am Miner. 2007;92:621-30.
89. Taoka A, Kondo J, Oestreicher Z, Fukumori Y. Characterization of uncultured giant rod-shaped magnetotactic Gammaproteobacteria from a freshwater pond in Kanazawa, Japan. Microbiol Read Engl. 2014;160:2226-34.

90. Monteil CL, Perrière G, Menguy N, Ginet N, Alonso B, Waisbord $\mathrm{N}$, et al. Genomic study of a novel magnetotactic Alphaproteobacteria uncovers the multiple ancestry of magnetotaxis. Environ Microbiol. 2018;20:4415-30. 